STEPHEN MORRIS

Princeton University

HYUN SONG SHIN

Princeton University

\title{
Financial Regulation in a System Context
}

ABSTRACT The global financial crisis raises questions about the proper objectives of financial regulation and how best to meet them. Traditionally, capital requirements have been the cornerstone of bank regulation. However, the run on the investment bank Bear Stearns in March 2008 led to its demise even though Bear Stearns met the letter of its regulatory capital requirements. The risk-based capital requirements that underpin the Basel approach to bank regulation fail to distinguish between the inherent riskiness of an asset and its systemic importance. Liquidity requirements that constrain the composition of assets may be a necessary complement. A maximum leverage ratio-an idea that has gained favor in the United States and more recently in Switzerlandmay also prove beneficial, deriving its rationale not from the traditional view that capital is a buffer against losses on assets, but rather from the importance of stabilizing liabilities in an interrelated financial system.

he global financial crisis of 2008 has raised fundamental questions long list of momentous events has been the demise of stand-alone investment banks in the United States. At the beginning of the year, the U.S. broker-dealer sector was dominated by five such banks: Bear Stearns, Goldman Sachs, Lehman Brothers, Merrill Lynch, and Morgan Stanley. By the end of September, three of the five (Bear Stearns, Lehman Brothers, and Merrill Lynch) had either gone bankrupt or been taken over by commercial bank rivals after suffering varying degrees of distress. The remaining two (Goldman Sachs and Morgan Stanley) were allowed to convert themselves into bank holding companies, thereby coming under the Federal Reserve's bank supervision umbrella. In the space of a few months, the era 
of the stand-alone Wall Street investment bank thus came to an end, and the market-based financial system that they epitomized became the object of intense scrutiny for clues as to what went wrong.

Traditionally, capital requirements have been the cornerstone of bank regulation. Their rationale lies in maintaining the solvency of the regulated institution, thus protecting the interests of creditors-especially retail depositors. ${ }^{1}$ As long as creditors are capable of monitoring a firm, they can protect their own interests by enforcing covenants and other checks on the actions of the firm's managers. However, the creditors of a traditional, deposit-funded bank are chiefly the small retail depositors, who face a coordination problem in monitoring the bank's managers and performing the other checks that large creditors are capable of. The purpose of bank regulation is seen as protecting the interests of depositors by putting into place, principally through capital requirements, the restrictions on the managers' actions that arise in normal creditor-debtor relationships.

This traditional rationale for capital regulation-protecting depositors by ensuring bank solvency-leads naturally to the conclusion that the key determinant of the size of the required capital buffer should be the riskiness of the bank's assets. After all, the degree to which solvency can be ensured depends on the likelihood that the realized value of the bank's assets will fall below the notional value of the creditors' claim. The original Basel capital accord of 1988 (Basel I, the first statement of bank regulatory principles to gain widespread international acceptance) introduced coarse risk classifications for bank assets. The Basel II rules, implemented in 2008, have taken the idea much further, refining the gradations of asset riskiness and fine-tuning the size of the capital buffer to the riskiness of the assets held by the bank.

However, the turmoil in the financial system witnessed in the current financial crisis poses a challenge to this traditional view of regulation. The Basel II regulations, which most of the world's developed economies are in the process of adopting, have largely been a bystander in the unfolding credit crisis that began with the subprime mortgage crisis in the United States.

In particular, recent events suggest that the traditional approach to financial regulation, based on institutional solvency and identifying solvency with equity capital, has come up short in its assigned task of ensuring system stability. The issue is highlighted in a recent open letter written

1. Dewatripont and Tirole (1994) discuss the underlying contract theory principles behind the prudential regulation of banks. 
by Christopher Cox, the chairman of the Securities and Exchange Commission (SEC), explaining the background and circumstances of the run on Bear Stearns in March 2008:2

The fate of Bear Stearns was the result of a lack of confidence, not a lack of capital. When the tumult began last week, and at all times until its agreement to be acquired by JP Morgan Chase during the weekend, the firm had a capital cushion well above what is required to meet supervisory standards calculated using the Basel II standard.

Specifically, even at the time of its sale on Sunday, Bear Stearns' capital, and its broker-dealers' capital, exceeded supervisory standards. Counterparty withdrawals and credit denials, resulting in a loss of liquiditynot inadequate capital—caused Bear's demise.

Thus, Bear Stearns got into trouble not because it failed to meet the letter of its regulatory capital requirements, but because its lenders stopped lending. Put differently, the problem was on the liabilities side of the balance sheet, rather than on the asset side.

One possible counterargument by Basel traditionalists might be to question the sharp distinction between solvency and liquidity in the SEC chairman's letter. They might argue that the run was triggered by concerns over asset quality, and a rapid sale of assets to meet the run would have revealed that Bear Stearns was insolvent. The coordination failure scenario painted by John Bryant and by Douglas Diamond and Philip Dybvig in the 1980s raises the possibility of a sound bank succumbing to a self-fulfilling run, ${ }^{3}$ but in practice, runs happen to weak banks. Strong banks, the counterargument goes, do not typically suffer runs, even though a run is always a logical possibility.

It is true that runs are typically associated with weak fundamentals. We will address this point in some detail in what follows. However, for policy purposes one needs to distinguish equilibrium outcomes from efficient outcomes. Even if it is difficult in practice to distinguish insolvent banks from illiquid banks, the distinction is nevertheless useful from a policy perspective, since one can then discuss the desirability of alternative policy measures to nudge the outcome in one direction or another.

Thus, the SEC chairman's point still needs to be addressed. Bear Stearns met the letter of its capital requirement, yet still suffered a run. We need to understand why, and whether better rules can be put in place.

2. Letter to the chairman of the Basel Committee on Banking Supervision, March 20, 2008 (www.sec.gov/news/press/2008/2008-48.htm).

3. Bryant (1980); Diamond and Dybvig (1983). 
In this paper we will argue that if the purpose of financial regulation is to ensure the stability of the financial system as a whole, then the traditional approach to financial regulation built around risk-based capital requirements is inadequate. In a system context, actions taken by financial institutions have spillover effects that affect the interests of other financial institutions. System stability then takes on the attributes of a public good, and like any public good, it is undersupplied by the market. Actions that are individually rational for each market participant lead to an inefficient outcome overall. The market fails. The objective of financial regulation in a system context, then, is to levy the appropriate Pigovian tax that mitigates these externalities to the extent possible, and thereby move the financial system as a whole closer to an efficient outcome.

Of particular importance is that there is a difference between the riskiness of an asset and the systemic importance of that asset. Sometimes, as we will demonstrate shortly, even an asset that is deemed very safe under the Basel approach may have an important systemic impact that arises from the way that financial intermediaries' claims are interwoven, and how those intermediaries react to unfolding events.

The system approach to financial regulation suggests that the current capital regime needs to be overhauled to accommodate two additions to the regulatory toolkit:

-First, there is a case for liquidity regulation, which places limits on the composition of a financial institution's balance sheet, and not merely on the size of its equity relative to its total assets.

- Second, even assets that have traditionally been viewed as very safe may justifiably face a regulatory capital charge. Indeed, a simple leverage constraint that does not take account of the riskiness of assets may be a better way to ensure system stability than the traditional risk-based capital charge.

Both these additional regulatory elements have much in common with several recent proposals by others for the reform of financial regulation. ${ }^{4}$ But besides some significant overlaps with these other proposals in terms of motivation, there are some differences in rationale and focus between those proposals and ours. Our discussion here is motivated by the debate on the regulation of the broker-dealer sector, and hence focuses on liquidity crises of the kind that undermined Bear Stearns, rather than on the general shortage of capital during a downturn. However, it is clear that the two

4. Such as that of Kashyap, Rajan, and Stein (2008). 
issues should be considered together in a comprehensive agenda for regulatory reform. We begin with some general remarks on the importance of a system perspective in financial regulation.

\title{
A System Perspective
}

Financial stability is best viewed from a system perspective, rather than from the point of view of each individual financial institution. Andrew Crockett has argued for distinguishing between the microprudential dimension of financial stability and the macroprudential one. ${ }^{5}$ The former has to do with the soundness of individual institutions, and the latter with the stability of the system as a whole. In his opening speech at the most recent Jackson Hole conference, Federal Reserve chairman Ben Bernanke argued for the superiority of the macroprudential perspective. ${ }^{6}$

A familiar truism holds that ensuring the soundness of each individual institution ensures the soundness of the system as a whole. Crockett makes the point that this statement is unhelpful, since it does not address how the soundness of all individual institutions is to be achieved simultaneously. ${ }^{7}$ Actions that ensure the soundness of one institution may not be consistent with ensuring the soundness of another. Unless there are good reasons to believe that policies that ensure the soundness of a particular institution will invariably promote the overall stability of the system, the prescription is a vacuous one.

Figure 1 offers a simple example, in the spirit of Franklin Allen and Douglas Gale. ${ }^{8}$ Bank 1 has borrowed from Bank 2. Bank 2 has other assets as well as its loans to Bank 1. Suppose that Bank 2 suffers credit losses on these other loans, but that the creditworthiness of Bank 1 remains unchanged. The loss suffered by Bank 2 depletes its equity capital. In the face of such a shock, a prudent course of action by Bank 2 is to reduce its overall exposure, trimming its asset book to a size that can be carried comfortably with the smaller equity capital.

The microprudential imperative is thus for Bank 2 to reduce its overall lending, including its lending to Bank 1. By doing so, Bank 2 achieves its microprudential objective of reducing its risk exposure. However, from Bank 1's perspective, Bank 2's reduction of its lending is a withdrawal of

\author{
5. Crockett (2000). \\ 6. Bernanke (2008). \\ 7. Crockett (2000). \\ 8. Allen and Gale (2000).
}


Figure 1. Bank Balance Sheets in a Simple Interbank Loan

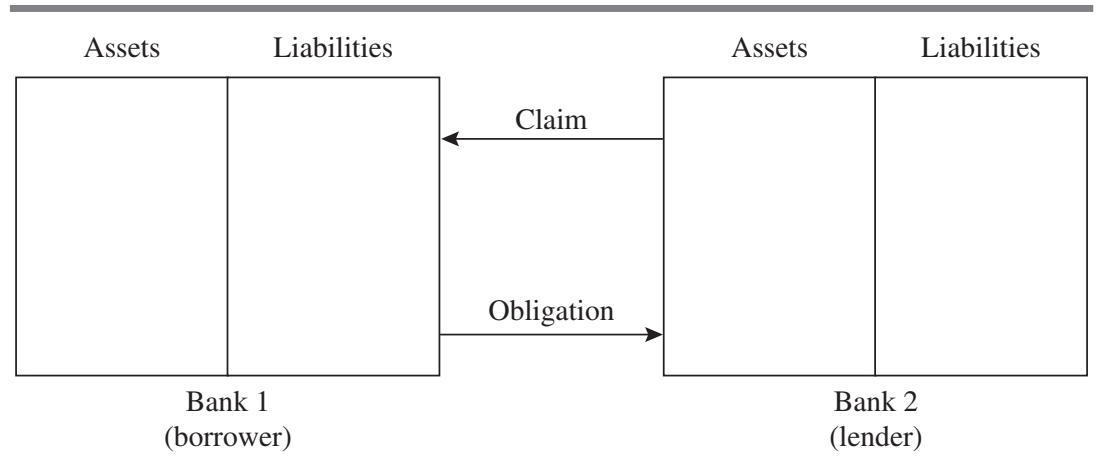

funding. Unless Bank 1 can find alternative sources of funding, it will have to reduce its own asset holdings, either by curtailing its lending or by selling marketable assets. If Bank 1 lacks alternative sources of funding, and if its assets are so illiquid that they can be sold only at fire-sale prices, then a large withdrawal of lending by Bank 2 will feel to Bank 1 no different from a run. In other words, a prudent shedding of exposures from the point of view of Bank 2 becomes a run from the point of view of Bank 1. Arguably, this type of run is what happened to the U.K. bank Northern Rock, which failed in 2007. The same perspective is useful in thinking about the run on Bear Stearns. In his March 2008 letter, SEC chairman Cox also says the following:

It is worth noting, however, that net capital rules are designed to preserve investors' funds and securities in times of market stress, and they served that purpose in this case. This investor protection objective was amply satisfied by the current net capital regime, which-together with the protection provided by the Securities Investor Protection Corporation (SIPC) and the requirement that SEC-regulated broker-dealers segregate customer funds and fully-paid securities from those of the firm-worked in this case to fully protect Bear's customers.

Indeed, the run on Bear Stearns did help to protect its investors' funds. But it did so in a way that had the undesirable effect of undermining Bear Stearns itself. From a system perspective, the run is an undesirable outcome, even if it served the microprudential objectives of Bear Stearns' creditors.

The lesson is that the microprudential imperative of ensuring solvency at the level of the individual institution may not ensure the macroprudential objective of system stability. The truism that ensuring the solvency of each individual institution achieves overall system solvency is unhelpful 
as a policy prescription, since enhancing the solvency of one institution may conflict with maintaining the stability of the system as a whole. Therefore, as a practical matter, it is important for policy to be formulated from a system vantage point from the outset.

Thus, our starting point is the following proposition:

Proposition 1: Actions that enhance the soundness of an individual financial institution may undermine the stability of the system as a whole.

The system perspective has the virtue of opening up for scrutiny the motivation of the creditors to a bank suffering a run, as well as the fundamentals of the bank itself. Consider the situation depicted in figure 2, where Bank 0 has $N$ creditors. These may include other banks, hedge fund clients who hold deposits at Bank 0, or money market mutual funds. For convenience, we label all creditors as "banks."

A run is associated with the self-confirming belief held by a creditor bank that when Bank 0's solvency comes into question, other creditors will take the prudent course of action and cut funding to Bank 0. This belief justifies cutting funding oneself. However, in practice, runs are associated with weak fundamentals on the part of the debtor bank and jitteriness on the part of creditors. If the debtor bank's fundamentals were stronger or its creditors more relaxed (or both), the run might be averted.

There is more at stake here than just the methodological point about finding the equilibrium. The hope is that if policymakers could engineer the initial conditions through appropriate regulation, so that the fundamentals of Bank 0 were stronger and the creditors less jittery, they could induce the stable, non-run outcome, instead of the run outcome.

A useful framework for thinking about this problem is provided by an example given by Lawrence Summers in his 2000 Ely Lecture. Summers proposed the following thought experiment:

Imagine that everyone who has invested $\$ 10$ with me can expect to earn $\$ 1$, assuming that I stay solvent. Suppose that if I go bankrupt, investors who remain lose their whole $\$ 10$ investment, but that an investor who withdraws today neither gains nor loses. What would you do? ...

Suppose, first, that my foreign reserves, ability to mobilize resources, and economic strength are so limited that if any investor withdraws I will go bankrupt. It would be a Nash equilibrium (indeed, a Pareto-dominant one) for everyone to remain, but (I expect) not an attainable one. Someone would reason that someone else would decide to be cautious and withdraw, or at least that someone would reason that someone would reason that someone would withdraw, and so forth.... 
Figure 2. Bank Balance Sheets with Lending by Multiple Banks

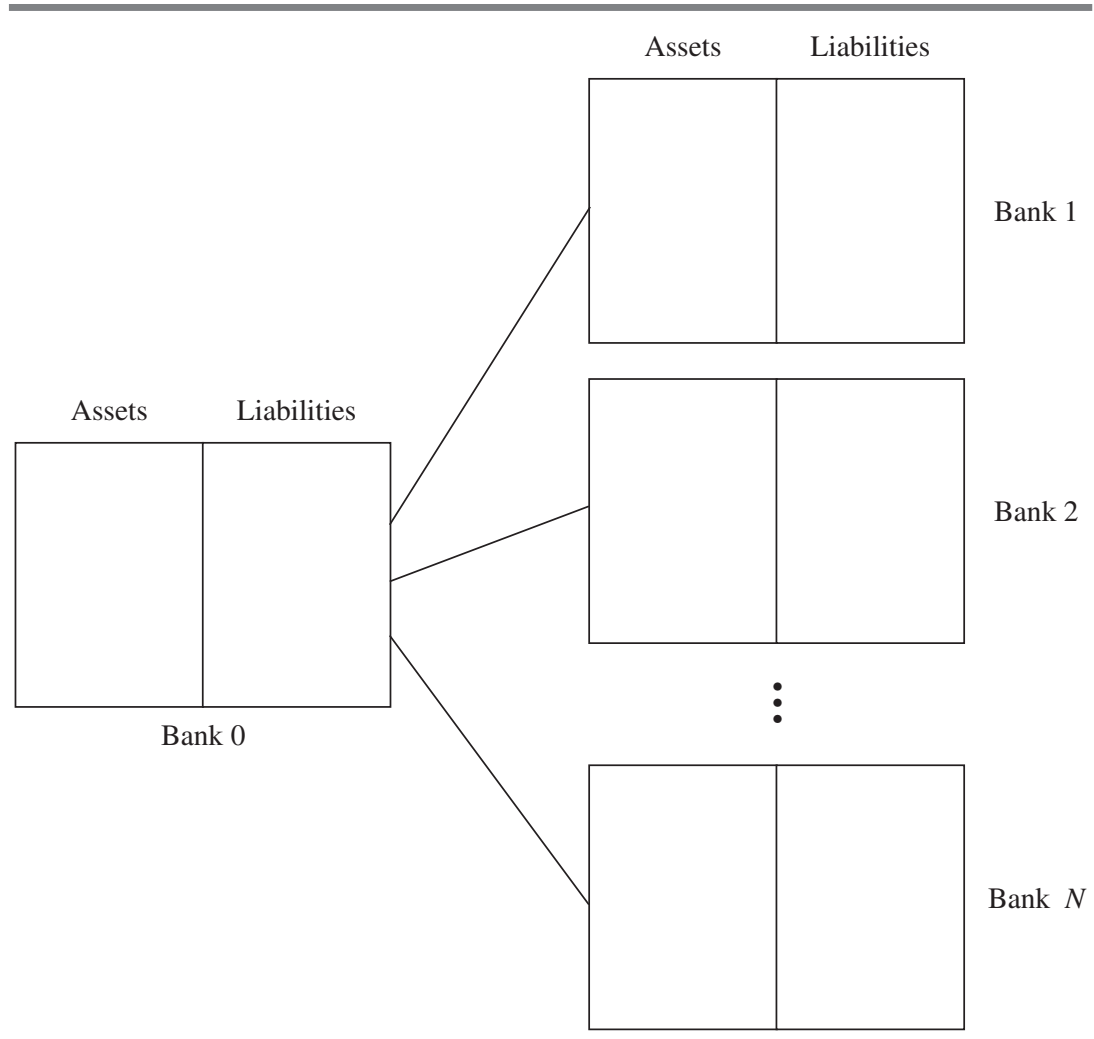

Now suppose that my fundamental situation were such that everyone would be paid off as long as no more than one-third of the investors chose to withdraw. What would you do then? Again, there are multiple equilibria: everyone should stay if everyone else does, and everyone should pull out if everyone else does, but the more favorable equilibria seems much more robust.

I think that this thought experiment captures something real. On the one hand, bank runs or their international analogues do happen. On the other hand, they are not driven by sunspots: their likelihood is driven and determined by the extent of fundamental weaknesses. ${ }^{9}$

The two dimensions to Summers' thought experiment are the same as in the example above: the strength of the fundamentals and the jitteriness of the creditors. But in Summers' formulation the first has to do with the threshold for the proportion of creditors who need to coordinate in order to

9. Summers (2000, p. 7). 
Figure 3. Global Game Analysis of Bank Coordination to Avoid a Run

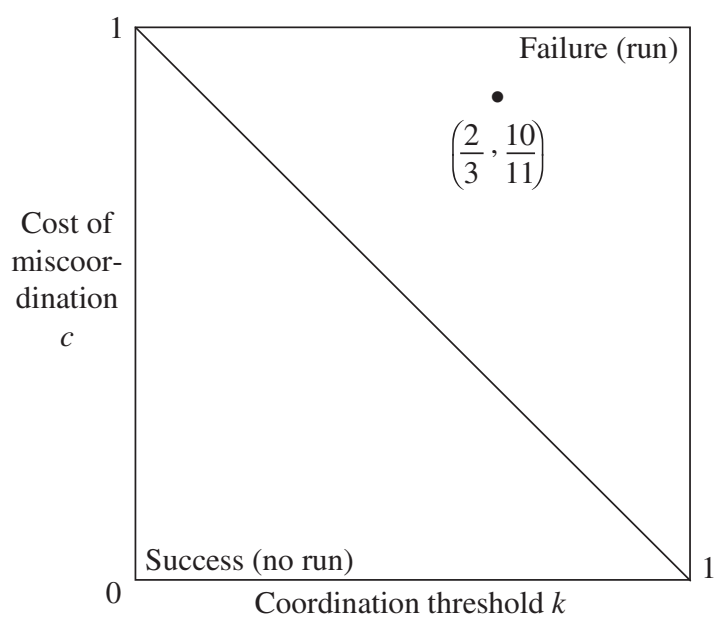

Source: Authors' model described in the text.

attain the good outcome. The weaker the fundamentals, the more fragile the borrower's balance sheet in the face of withdrawals. Summers appeals to our strong intuition that if the threshold value for coordination is close to one, coordination is very difficult to achieve. If the threshold is much less, coordination is easier.

The second dimension relates to the potential cost of miscoordination. In Summers' example the potential cost of failing to coordinate is losing one's stake of $\$ 10$, whereas the reward to successful coordination is $\$ 11$. The higher the cost of miscoordination, the more jittery the creditors will be. Again, our intuition would be that when the costs of miscoordination are high, coordination is more difficult to achieve.

It is possible to solve the Summers game using global game methods and verify that the two dimensions of the problem determine the unique equilibrium outcome. ${ }^{10}$ This idea is depicted diagrammatically in terms of the unit square in figure 3. The horizontal axis plots the coordination threshold $k$, that is, the proportion of creditors who need to remain invested in order to achieve the good outcome. The vertical axis measures the cost of miscoordination $c$, expressed as a proportion of the payoff to successful coordination.

The global game analysis confirms the strong intuition articulated by Summers: successful coordination is achieved in the bottom left corner of

10. See Morris and Shin (2002). 
the unit square (where the threshold for coordination is low and the cost of miscoordination is low), whereas in the opposite corner (where both the threshold for coordination and the cost of miscoordination are high) the good outcome cannot be achieved. The exact dividing line between the good and the bad regions depends on other parameters of the global game, but the benchmark dividing line is the straight line that cuts the unit square through the diagonal.

We can use this global game analysis to further test our intuitions. For the parameter values given by Summers in his thought experiment, the corresponding point in the unit square is $(2 / 3,10 / 11)$, since at least two-thirds of investors need to keep their money in, the cost of miscoordination is $\$ 10$, and the payoff of the good outcome is $\$ 11$. This point therefore lies in the failure region. The global game analysis thus suggests that Summers may have been too sanguine about the possibility of forestalling the run. But specific cases aside, the more general lesson is that coordination failure can be remedied by changes in the environment that make banks more robust to withdrawals, or by changes that lower the opportunity cost of miscoordination. ${ }^{11}$

In the banking context, if the debtor bank held more cash in place of illiquid assets, it could meet withdrawals more easily, thereby lowering the threshold $k$ for coordination among the creditor banks. The cost of miscoordination $c$ for the creditor banks could also be reduced if they held more cash, since they would then be less vulnerable to a run themselves. A more liquid creditor bank would be less jittery. It is thus possible to formalize within a global game the idea that greater cash holdings reduce the fragility of an institution's balance sheet to potential runs. ${ }^{12}$

Thus, to anticipate one of our conclusions, liquidity requirements on banks may reduce the potential for runs through two channels: they make debtor banks more robust to withdrawals, and they make creditor banks less trigger-happy. Recognition of the second channel is an insight that can only be gained in a system context.

11. This was a line of argument we pursued in our earlier paper on currency attacks (Morris and Shin, 1998).

12. In Morris and Shin (2008) we provide a formal decomposition of an institution's total credit risk into the risk of failure due to asset insolvency unrelated to a run by creditors, and the risk of failure purely due to a run. We examine how each of these components of credit risk depends on balance sheet composition and verify that greater cash holdings reduce total credit risk beyond the reduction attributable to the fall in the riskiness of the assets. 
On the same theme, any institutional feature that constrains creditors in the direction of curtailing lending in reaction to events will undermine system stability. A prominent example in the context of Bear Stearns is the role of the triparty repurchase agreements (repos) that Bear Stearns entered into with certain money market mutual funds. In these agreements, Bear Stearns pledged illiquid securities as collateral, in return for which the money market funds provided Bear Stearns short-term funding. The transaction was overseen by a central counterparty that held the collateral and administered the payments.

The problem with this arrangement was that under their charters, most money market funds are prevented from holding illiquid securities of the type pledged by Bear Stearns. Thus, if Bear Stearns had become illiquid, and the assets pledged as collateral reverted to the money market funds, they would have been forced to sell those assets quickly, possibly at a large loss. This might have forced the funds to "break the buck"; that is, the value of their assets might have fallen below par value. Until Lehman Brothers' bankruptcy in September 2008, no money market fund had ever broken the buck. Therefore the Federal Reserve was concerned that such losses would have opened up the prospect of a run by retail investors on the entire money market mutual fund sector, by changing their perception of the funds' safety.

Some commentators have described the money market funds as extremely risk averse, but a more accurate description of their motivation is in terms of the cost of miscoordination. In effect, the cost of miscoordination $c$ that these funds faced was extremely high. Hence, they heeded the imperative to be prudent and withdrew their funding to Bear Stearns. This in turn made other creditors, such as Bear Stearns' hedge fund clients, less willing to leave their money with the company as well.

The involvement of money market mutual funds in the triparty repo is an instance where institutional constraints made the run outcome more likely. It suggests that reform of institutional arrangements could change the underlying payoffs in the coordination game in the direction of making the system less fragile. We summarize this lesson as follows:

Proposition 2: A run is more likely when the coordination threshold is high or when the cost of miscoordination is high. Policies that lower the coordination threshold or the cost of miscoordination are likely to promote system stability.

The system perspective also raises an important distinction between the fundamental riskiness of an asset and its systemic importance. Even if an 
Figure 4. Bank Balance Sheets with Reselling of Repo Securities

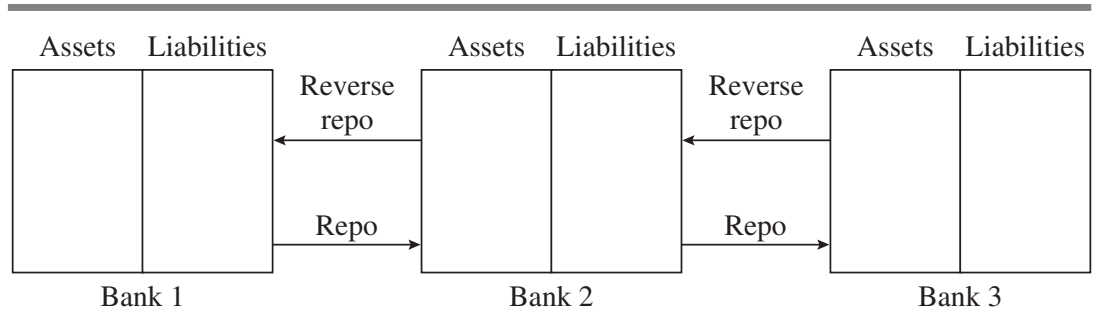

asset is very safe from the point of view of its credit risk profile, it may have a large impact on the stability of the system as a whole.

Consider the example illustrated in figure 4. Here Bank 1 holds mortgage-backed securities (MBSs) as its assets and finances this holding with overnight repos, in effect pledging the securities as collateral. In such an arrangement, Bank 1 actually sells the securities to another party (Bank 2 in this example) with the understanding that it will buy them back the next day at a prearranged price. Then, at the end of each day, the transaction is repeated. The repo thus enters as a liability on Bank 1's balance sheet and as a reverse repo on the asset side of Bank 2's balance sheet.

Bank 2, for its part, funds its lending to Bank 1 by pledging the same securities to another bank (Bank 3). Thus, Bank 2's balance sheet contains overnight reverse repos issued to Bank 1 on the asset side and overnight repos issued to Bank 3 on the liabilities side.

From Bank 2's perspective, its assets are extremely safe, for two reasons. First, the assets are short term, and so the range of possible realizations of their value is small. Second, the loan is fully collateralized, so that even if Bank 1 cannot repay, Bank 2's claim is protected. Furthermore, the maturity profiles of the two sides of Bank 2's balance sheet match perfectly. Both its assets and its liabilities involve overnight transactions. Hence, Bank 2 can react to any change in the environment by flexibly reducing the size of its balance sheet. By reducing the amount of the reverse repo to Bank 1 that it is willing to roll over, it can reduce its asset exposure. It is also in a good position to meet any run on its liabilities. If Bank 3 refuses for some reason to roll over the overnight repos, Bank 2 can immediately respond by refusing to roll over its reverse repos to Bank 1 . In this sense Bank 2 is a very safe bank. The capital required of Bank 2 under Basel standards would be extremely low, and therefore Bank 2 could attain a very high degree of leverage. The Basel perspective justifies the high leverage by appealing to the safe nature of Bank 2's assets when viewed in isolation. 
However, Bank 2's assets are also important from a system perspective, because they are the mirror image of Bank 1's liabilities. If Bank 1 's assets are illiquid, such that they cannot realize much value in a fire sale, the impact on Bank 1's solvency of a run on its liabilities would be severe. If Bank 2 refused to roll over its overnight reverse repos issued to Bank 1, Bank 1 would be forced to sell its MBS assets unless it can find alternative sources of funding (say, from the central bank). Thus, even though they are very safe from the point of view of credit risk, Bank 2's assets have a high systemic impact. This leads to our third proposition:

Proposition 3: There is a distinction between risky assets and systemically important assets. Even safe assets can be systemically important.

The distinction between risky assets and systemically important assets takes on added significance in a market-based financial system built around the practice of secured lending through repos. One feature of a repo is that the "borrower" sells the securities today for a price below their current market price, because the understanding is that the borrower will later buy the securities back at a preagreed price. The difference between the current market price of the security and the price at which it is sold in the repo is called the "haircut."

The systemic impact of collateralized lending is especially strong when the haircut on the repo contract fluctuates in response to market conditions. The reason is that the haircut determines the maximum permissible leverage achieved by the parties involved. In terms of figure 4, suppose that the haircut on Bank 1's repos is 2 percent, so that Bank 1 receives $\$ 98$ for $\$ 100$ worth of securities sold. Then, to hold $\$ 100$ worth of securities, Bank 1 must come up with $\$ 2$ of equity. Thus, if the repo haircut is 2 percent, the maximum permissible leverage (ratio of assets to equity) is $50: 1$.

Suppose that Bank 1 leverages up to this maximum permitted level. Such action would be consistent with the objective of maximizing the return on equity, since leverage magnifies the return on equity. If a shock to the financial system then raises the haircut to, say, 4 percent, the permitted leverage falls by half, from 50:1 to 25:1. Bank 1 then must either raise new equity so that its equity doubles, or sell half its assets, or some combination of the two.

Times of financial stress are associated with sharply higher haircuts, which in turn entail substantial reductions in leverage, necessitating asset 
disposals or raising of new equity. Raising new equity is notoriously difficult in distressed market conditions, but selling assets in a depressed market is not much better. The evidence suggests that banks typically do the latter, leaving equity intact. ${ }^{13}$ Thus, fluctuations in leverage are associated with pronounced fluctuations in the willingness to lend.

To the extent that the financial system as a whole holds long-term, illiquid assets financed by short-term liabilities, any tensions resulting from a sharp increase in repo haircuts will show up somewhere in the system. Even if some institutions can flexibly adjust their balance sheets downward in response to the greater stress, this action will itself expose pinch points in others.

These fluctuations in leverage in the context of widespread secured lending expose the myth of the "lump of liquidity" in the financial system. It is tempting to be misled by our use of language into thinking that "liquidity" refers to a fixed stock of available funding in the financial system, which will be redistributed to those who need it most. So, for instance, in the examples given in figures 1 and 2, the idea would be that when funding from one creditor dries up, the borrower can tap alternative sources. In reality, when liquidity dries up, it disappears altogether rather than being reallocated elsewhere. When haircuts rise, all balance sheets shrink in unison, leading to a generalized decline in the willingness to lend. Liquidity should therefore be understood in terms of the growth of balance sheets, that is, as a flow rather than as a stock. ${ }^{14}$

Indeed, the very term "secured lending" suggests that the assets are safe in terms of credit risk, since the loan is secured by collateral. However, funding conditions overall will vary substantially as haircuts fluctuate. Figure 4 illustrates the fact that fluctuations in Bank 2's assets have a systemic impact, even though Bank 2 is safe from credit risk. In this way the riskiness of an asset can diverge from its systemic impact. The Basel perspective, which focuses only on the credit risk of the asset, obscures this important distinction.

The distinction between risky assets and systemically important assets turns out to be crucial for broker-dealers, since many of the items on the balance sheet of an investment bank are precisely those that are collateralized and short term. Thus, as a prelude to our main discussion, we first examine the balance sheet characteristics of broker-dealers.

13. Adrian and Shin (2008, forthcoming).

14. Adrian and Shin (forthcoming); Fisher (2008). 


\section{Broker-Dealer Balance Sheets}

Broker-dealers, a category of financial institutions that includes the major investment banks, differ sharply in the composition of their balance sheets from the archetypal deposit-funded bank. Figure 5 summarizes the balance sheet of Lehman Brothers as of November 30, 2007, the end of its financial year.

The two largest classes of Lehman Brothers' assets on that date were long positions in trading assets and other financial inventories, and collateralized loans. The latter reflect Lehman's role as prime broker to hedge funds and other borrowers and include reverse repos. Much of this lending was short term and therefore very safe from a credit risk perspective. Such loans are precisely the type of assets that could be systemically important even though their credit risk may be small.

The other remarkable feature of the asset side of Lehman Brothers' balance sheet is its small holding of cash: $\$ 7.3$ billion out of a total balance sheet of $\$ 691$ billion. However, this figure would be an underestimate of the cash that the company could have raised at short notice, if the securities holdings included liquid securities.

Lehman Brothers' liabilities, meanwhile, were largely short term. The largest component was collateralized borrowing, including repos. Short positions ("financial instruments and other inventory positions sold but not yet purchased") were the next largest component. Long-term debt made up only 18 percent of total liabilities.

One notable item, accounting for 12 percent of Lehman's balance sheet, was "payables," which included the cash deposits of Lehman's customers, especially its hedge fund clientele. These "payables" were much larger than the "receivables" on the asset side, which amounted to only 6 percent of the balance sheet. Hedge fund customers' deposits are subject to withdrawal on demand and hence may be an important source of funding instability. We will return to this issue when we discuss Bear Stearns' balance sheet and that company's more prominent reliance on payables to customers.

Finally, note that Lehman's equity ( $\$ 22.5$ billion) was only 3 percent of its total assets, implying a leverage ratio of $30.7: 1$. This is a much higher number than for commercial banks, which typically maintain a leverage ratio of 10:1 to 12:1. The higher leverage of investment banks reflects both the relatively low credit risk of the assets held and the short-term nature of much of their claims and obligations. Indeed, Lehman's end-2007 balance sheet as a whole consisted of precisely the types of assets and liabilities that have low credit risk but high systemic impact. 
Figure 5. Composition of Lehman Brothers' Balance Sheet, November 30, 2007

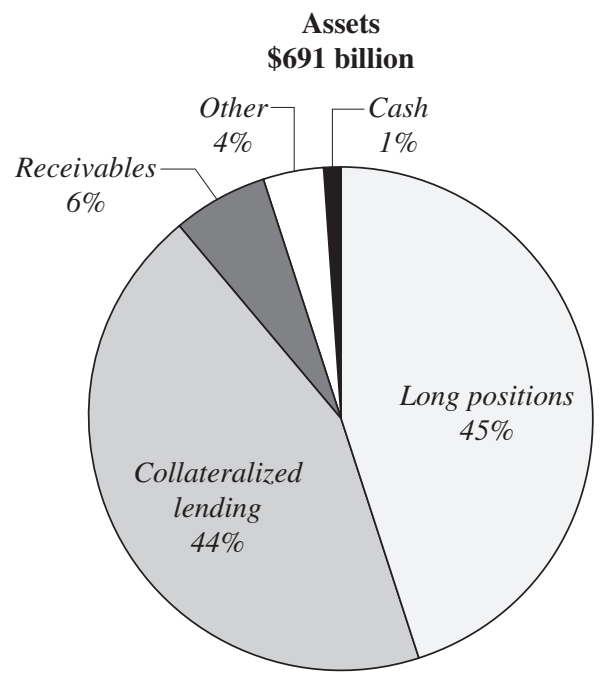

Liabilities

\$691 billion

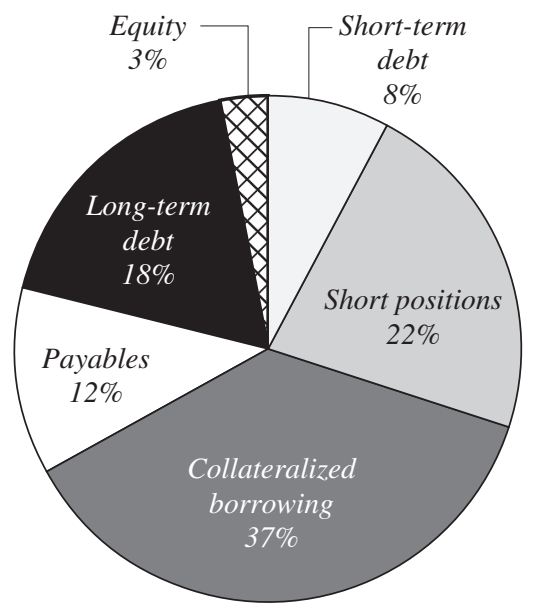

Source: Lehman Brothers 2007 annual report. 
The balance sheet for Bear Stearns as of the same date (summarized in figure 6) shares many of the same characteristics noted for Lehman Brothers, but there are also some notable differences. As at Lehman, long positions in securities and collateralized lending formed the bulk of the company's assets. However, Bear Stearns' long positions also included the assets of special-purpose entities that were consolidated with Bear Stearns' own assets in accordance with standard accounting rules..$^{15}$ The liabilities of the special-purpose entities were also consolidated with those of the parent and were thus a counterpart to the asset holdings. Since these entities funded themselves mainly with short-term borrowing (such as commercial paper), the liability item "short-term debt" on Bear Stearns' balance sheet includes the liabilities of such entities.

One notable feature of Bear Stearns' balance sheet is the large proportion of funding - fully 22 percent of the total—consisting of payables. As with Lehman Brothers, the bulk of these payables were deposits of hedge fund customers, reflecting the importance of Bear Stearns' prime brokerage business. Also as at Lehman, they made Bear Stearns vulnerable to a classic run in the event of coordination failure among the hedge fund customers. Such a coordination failure might have reinforced whatever increase in repo haircuts already prevailed in the market.

In fact, during the run on Bear Stearns in March 2008, the defection of its hedge fund clients was one of the factors contributing to the funding shortage that eventually led to the company's request for Federal Reserve support. The Wall Street Journal's special feature on Bear Stearns in May 2008 reported that several hedge funds and other customers had pulled their funds out of Bear Stearns at the height of the crisis in March. ${ }^{16}$

Figure 7, which plots the cash holdings of Bear Stearns in the days leading up to its demise, shows that in the three days from March 10 to March 13, these holdings dropped sharply, from $\$ 18$ billion to only $\$ 2$ billion. The speed with which the cash was exhausted shows the role played by the instability of liabilities in leading to the institution's failure. Thus, contrary to the traditional focus on credit risk on the asset side of the balance sheet, what mattered in the Bear Stearns case was the run on the liabilities side. To the extent that broker-dealer balance sheets

15. These rules stipulate that when the sponsor is the main beneficiary of the specialpurpose entity and exercises substantial control over it, the entity should be considered as part of the sponsoring bank and their assets consolidated.

16. "The Fall of Bear Stearns: Fear, Rumors Touched Off Fatal Run on Bear Stearns," Wall Street Journal, May 28, 2008, p. A1. 
Figure 6. Composition of Bear Stearns' Balance Sheet, November 30, 2007

Assets

$\$ 395$ billion

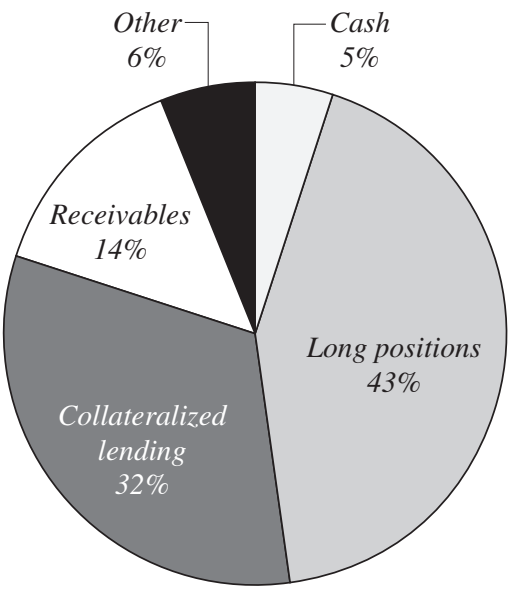

Liabilities

\$395 billion

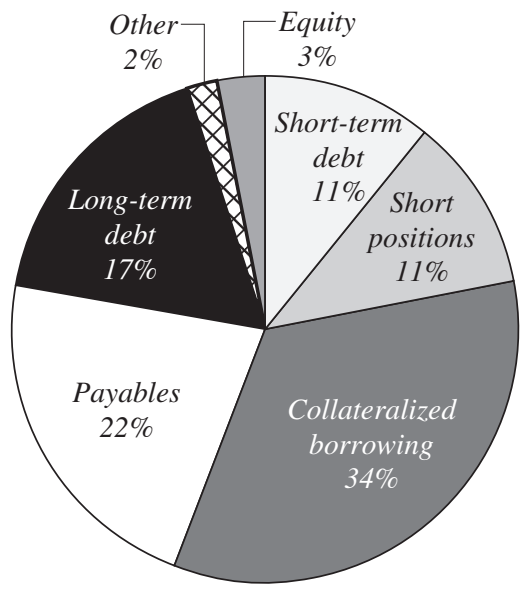

Source: Bear Stearns 10-K for fiscal 2007. 
Figure 7. Bear Stearns' Cash Holdings, February 22-March 13, 2008

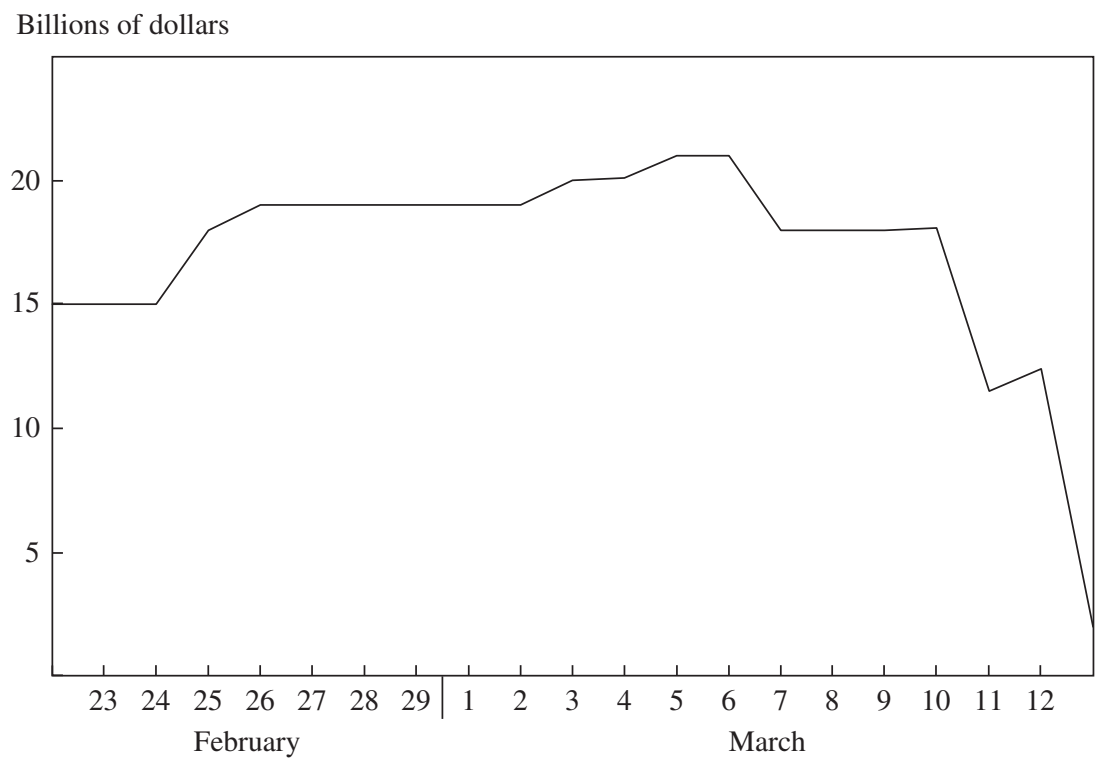

Source: Letter from SEC Chairman Christopher Cox to the Chairman of the Basel Committee on Banking Supervision, March 20, 2008.

consist primarily of such liquid and short-term claims and obligations, the run on Bear Stearns holds many useful lessons.

\section{Implications for Financial Regulation: Liquidity Regulation}

We now turn to the policy implications of our analysis so far. Our discussion is organized around the examples and propositions presented above. Returning to the case illustrated in figure 2, think of Bank 0 as a bank such as Northern Rock, the U.K. bank that failed in 2007, or as Bear Stearns, which financed its long-lived, illiquid assets by relying on short-term wholesale funding in the capital market. The exact identity of the lenders will differ from case to case, but the essence of the problem is this mismatch of maturities.

In this context, liquidity requirements on all banks, both debtors and creditors, might reduce the potential for runs through two channels: by making debtor banks more robust to withdrawals, and by making creditor banks less trigger-happy. Figure 8 illustrates this point using the Summers game described earlier. Point A on the parameter space is associated with a 
Figure 8. Global Game Analysis of Bank Coordination with Liquidity Requirements

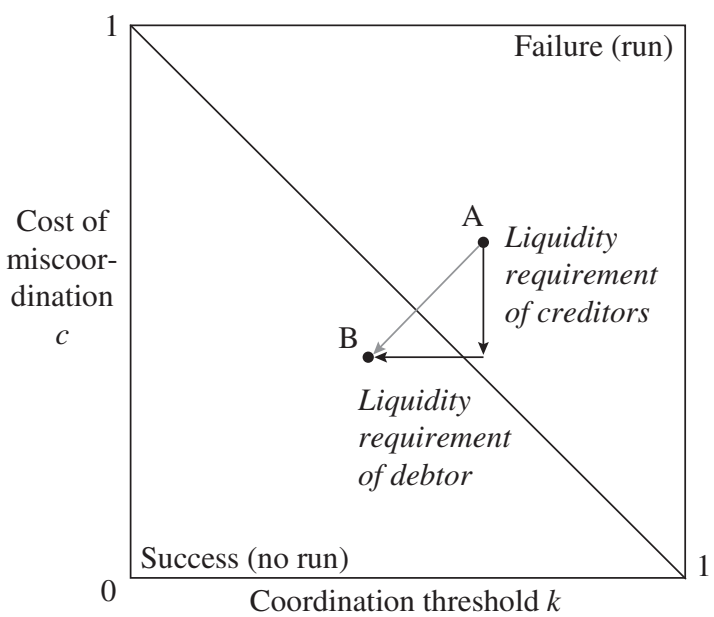

Source: Authors' model described in the text.

run outcome. It depicts a fragile arrangement where both the coordination threshold $k$ and the cost of miscoordination $c$ are high. A liquidity requirement on the debtor bank (Bank 0) would lower the critical threshold $k$, by making the debtor more robust to withdrawals, since moderately sized withdrawals can now be met by the debtor bank's liquid asset holdings. The liquidity requirement would also lower the cost of miscoordination $c$ by making the creditor banks (Banks 1 to $N$ ) themselves less vulnerable to a deterioration of funding conditions.

The figure suggests that liquidity requirements might not have to be very onerous to be effective. Just as the fragility of the original arrangement sets in motion a vicious circle of reasoning that leads to the run, so the increased robustness achieved through higher liquidity would set in motion a virtuous circle of reasoning leading to a stable outcome. A more robust debtor bank would instill confidence in the creditor banks, which in any case will be more relaxed about the actions of other creditor banks in the face of worsening funding conditions.

How onerous the liquidity requirements must be to achieve the stable outcome would depend on the circumstances. A more systematic investigation, using both theoretical modeling and numerical simulations, would be worth pursuing. However, the important principle is that liquidity requirements would work by harnessing precisely those externalities that cause a run in the first place. The Summers game may oversimplify the compari- 
son, but the same type of analysis can be brought to bear in an actual market context, as we have shown elsewhere. ${ }^{17}$ In that analysis the model is set in a more complex environment with more parameters to be considered, such as the elasticity of the residual demand curve that absorbs concerted selling. However, the underlying principles are identical to those in the Summers game, and a unique outcome can be associated with each parameter configuration.

In addition, the underlying principle of distinguishing the credit risk of assets from their systemic impact seems important in any exercise of this sort, since the holding of cash buffers will affect the actions of interrelated players in subtle ways. As can be seen in figure 8, the (unique) equilibrium outcome can shift abruptly in response to small shifts in the underlying parameters of the problem that vary the susceptibility of the system to runs.

Recognizing the mutually reinforcing nature of banks' actions holds out some hope that the liquidity requirements sufficient to preclude a run might be rather modest, provided they are widely adopted. More systematic investigation will reveal precisely how onerous the liquidity requirements need to be to ensure stability. In such an exercise, there will be inevitable trade-offs between the size of the shocks contemplated and the liquidity requirements needed to meet those shocks. Numerical simulations will reveal the terms of that trade-off.

The actual cash holdings of U.S. broker-dealers have been relatively stable over the last 25 years or so, fluctuating between 2 and 4 percent of assets in recent years. Figure 9 traces this ratio for the whole of the U.S. broker-dealer sector since 1983, as given by the Federal Reserve's Flow of Funds Accounts. The sharp peak in 1987 and 1988 is associated with the stock market crash of 1987 . Increases in cash holdings also occurred in 2000-02 (associated with the bursting of the dot-com bubble) and in the most recent couple of quarters (associated with the current credit crisis).

Interestingly, the relatively stable path for cash holdings for brokerdealers is not matched in the comparable series for U.S. commercial banks. As figure 10 shows, the ratio of cash assets (vault cash, cash items in process of collection, balances due from depository institutions, and balances at the Federal Reserve) to total financial assets of U.S. commercial banks has declined steadily in recent decades. As Tim Congdon has noted, the decline in cash holdings for U.K. banks has been, if anything, even 
Figure 9. Cash Holdings of U.S.-Based Broker-Dealers, 1983Q2-2008Q1

Percent of total financial assets ${ }^{\mathrm{a}}$

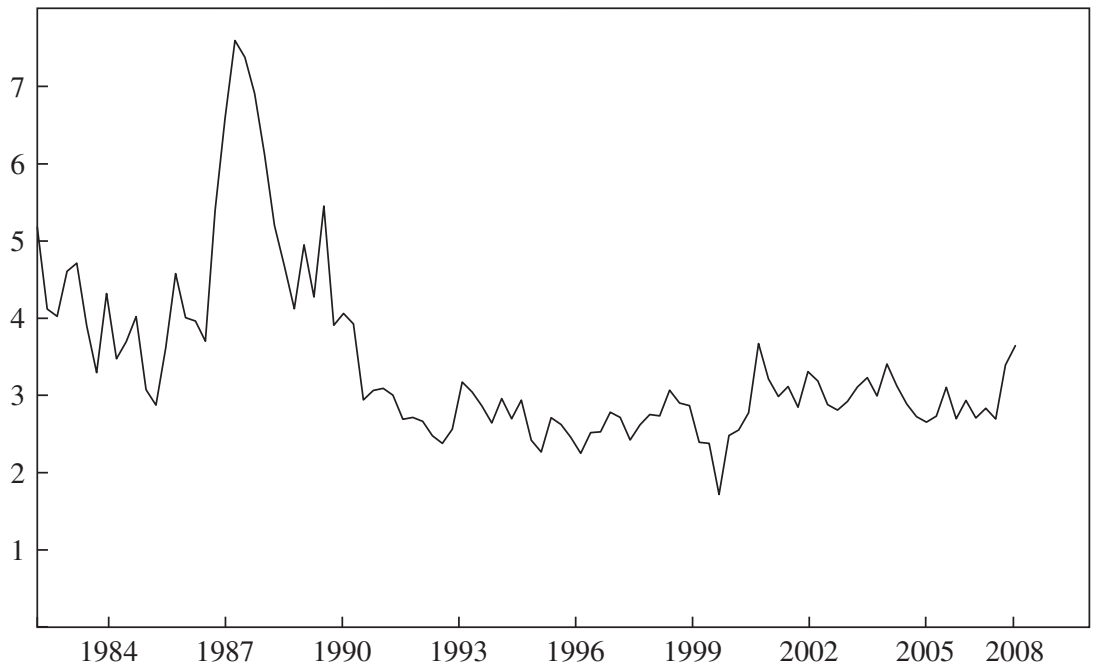

Source: Federal Reserve, Flow of Funds Accounts of the United States.

a. As of the end of the quarter.

Figure 10. Cash Holdings of U.S.-Based Commercial Banks, December 1981-June 2008

Percent of total financial assets ${ }^{\mathrm{a}}$

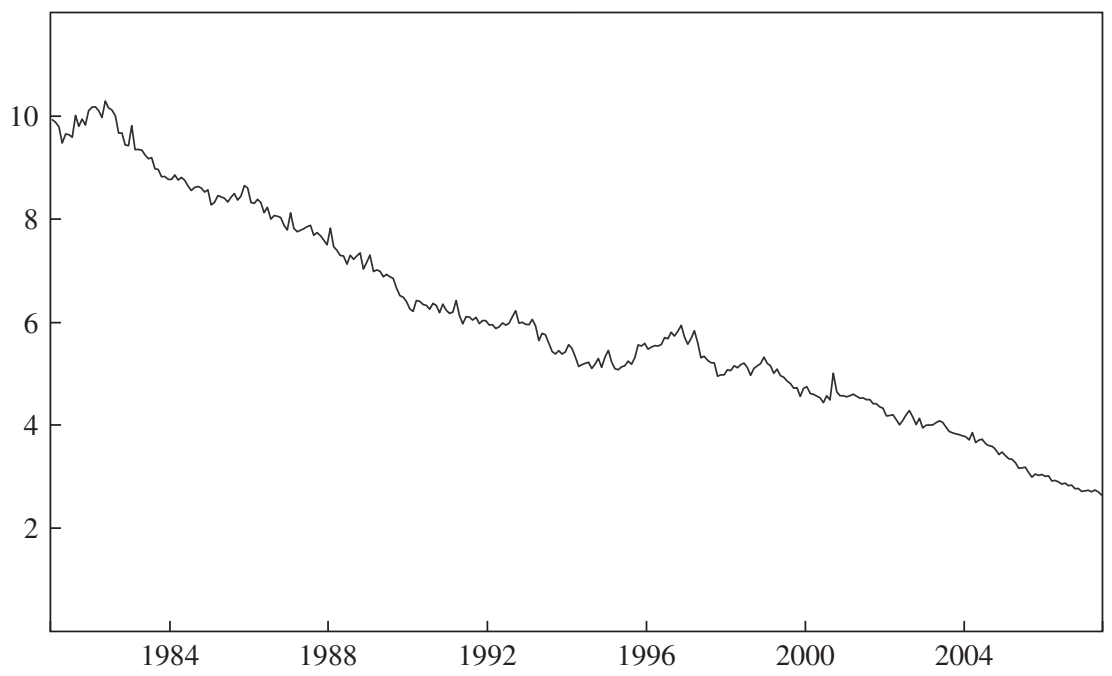

Source: Federal Reserve, "H.8 Assets and Liabilities of Commercial Banks in the United States: Historical Data."

a. As of the end of the month. 
more dramatic. ${ }^{18}$ In the 1950 s it was typical for U.K. banks to hold as much as 30 percent of their assets in liquid form. However, Congdon reports that in the aggregate, their ratio of liquid assets to total assets has fallen to 1.0 percent in recent years. The Bank of England's Financial Stability Report of April 2008 charts bank liquidity ratios according to several definitions and confirms that the liquid asset holdings of U.K. banks have fallen sharply in recent decades. ${ }^{19}$

Although liquidity requirements might mitigate the potential for runs, the institutional constraints imposed on particular types of market players should also be taken into account. The triparty repo agreement involving money market mutual funds, discussed earlier, injects elements of greater fragility by involving players that are constrained to cut back on lending when financial conditions deteriorate.

We have already mentioned that money market mutual funds can be seen as creditors whose cost of miscoordination $c$ is extremely high. Since the cost for these entities arises from the nature of the business and the charter that constrains their actions, liquidity requirements on them are unlikely to have much effect. This suggests a strong case for regulating their role in the triparty repo market.

Liquidity requirements would be complementary to other reforms of capital regulation to mitigate the cyclical nature of risk taking by financial intermediaries and the shortage of capital during a downturn. Although we have focused here on runs on the liability side, it is important to place such liquidity crises in the overall context of the credit cycle.

Anil Kashyap, Raghuram Rajan, and Jeremy Stein have recently proposed a regulatory scheme that would incorporate an element of funded capital insurance for banks. Banks would pay into a fund that holds safe securities in a "lockbox," to be opened in the event that certain defined aggregate thresholds of financial distress have been crossed..$^{20}$ The time necessary to verify that a threshold has been crossed makes the capital insurance scheme better suited for addressing a shortage of capital in the down phase of the financial cycle, and suggests that such a trigger mechanism could be seen as having a longer-term focus than the very short term acute liquidity shortages envisaged in a liquidity crisis. However, liquidity requirements and capital should be considered together in any reform of the regulatory framework.

18. Tim Congdon, "Pursuit of Profit Has Led to a Risky Lack of Liquidity." Financial Times, online edition, September 10, 2007. www.ft.com/cms/s/0/04ead7fc-5f36-11dc-837c0000779fd2ac.html.

19. Bank of England (2008).

20. Kashyap, Rajan, and Stein (2008). 


\section{Implications for Financial Regulation: Leverage Constraints}

We now turn our attention to another possible regulatory tool, namely, a constraint on the overall leverage of banks and brokers. We organize our discussion around the case illustrated in figure 4 . The scenario we consider is one of a generalized increase in haircuts in the capital markets. Specifically, we assume that Bank 1 experiences funding problems that result from an increase in the haircut on its repo transactions with Bank 2. The increase in repo haircuts does damage because repo haircuts were previously very low and had encouraged all the banks in the system to increase their leverage.

Any discussion of proposed policies should be based on a clear set of objectives that those policies are intended to achieve. We will take as a working assumption that the purpose of financial regulation is to reduce the amplitude of financial booms and busts, and particularly the externalities generated by such a boom-and-bust dynamic.

One policy proposal that has already attracted considerable attention would impose a maximum leverage constraint on banks, without assigning any weights to the assets that figure in the leverage calculation. The United States has been at the forefront of such an initiative. ${ }^{21}$ Although such constraints have been criticized as being too blunt, the system perspective provides a rationale. A leverage constraint has the potential to prevent the buildup in leverage that leaves the system vulnerable to a sudden reversal. The idea is that the maximum leverage constraint is a binding constraint on the upside of the cycle, when funding conditions are ample and banks can increase their leverage easily. The buildup of excessive leverage makes the system vulnerable to an increase in haircuts.

Note that an increase in haircuts does the most harm when starting from very low levels. For example, an increase from 1 to 2 percent means that leverage has to fall by half, from 100:1 to 50:1. But an increase from 20 to 21 percent, still only 1 percentage point, would have only a marginal effect, reducing leverage from 5.0:1 to about 4.8:1. In this sense the chasing of yield at the peak of the financial cycle is especially precarious, since the unwinding of leverage in the subsequent downturn will be that much more potent.

By preventing the buildup of leverage during good times, the leverage constraint could act as a dampener in the financial system. As with any constraint that threatens actually to bind, the banks will complain of being

21. See the speech by the chairperson of the Federal Deposit Insurance Corporation, Sheila Bair (2006). 
prevented from pursuing higher profits. However, this is as it should be, since any Pigovian tax is just that $-\mathrm{a}$ tax.

The leverage constraint would work both at the level of the debtor and at the level of the creditor. In terms of figure 4, the constraint would prevent Bank 1 (the debtor) from building up excessive leverage, making it less susceptible to an uptick in the repo haircut. Meanwhile the constraint would also bind on Bank 2 during an upswing, so that when eventually the tide turns, some slack would remain available in Bank 2's balance sheet capacity. Hence, its lending to Bank 1 would suffer a smaller shock from any rise in repo haircuts. Thus, for both lender and borrower, the leverage constraint binds during boom times, so that the imperative to reduce leverage is less strong in the bust. Indeed, the bust may be averted altogether.

The fluctuations in leverage implied by the haircut in secured lending transactions suggest that banks and brokers expand their balance sheets to the maximum extent allowed by prevailing market conditions, only to cut back their balance sheets when funding conditions deteriorate. The imperative to maximize the return on equity could be one reason for such behavior. The externalities are manifested only in the down phase, but the potential for those externalities was created in the up phase. The rationale for a leverage constraint is that it binds during the expansion phase of the cycle, inviting the banks either to raise new equity or to slow balance sheet growth.

Also important to bear in mind is that the sharp increase in repo haircuts during a crisis episode is endogenous. The severity of the crisis depends on both the extent of the preceding boom and the actions of market participants. ${ }^{22}$ When leverage unwinds, the force of the unwinding will be stronger when the boom has gone on longer and excesses have been allowed to persist. One of the desired effects of the leverage constraint is to dampen the fluctuations in repo haircuts themselves.

In effect, a leverage constraint can be considered a capital requirement that is not risk-sensitive: safe assets attract the same regulatory capital requirement as risky assets. It is important to emphasize the difference in rationale between the leverage constraint considered here and the traditional risk-based capital requirement. As discussed already, the credit risk of reverse repos is small, so that under Basel-style regulation, the required capital is likewise small. However, a leverage constraint would have the effect of mitigating the externalities generated by the fluctuations

22. Brunnermeier (2009) and Brunnermeier and Pedersen (forthcoming) describe the mechanisms at play when funding and market liquidity combine to amplify the financial distress. 
in funding conditions in a market-based financial system built around secured lending. The focus is on the liabilities side of balance sheets, and on the potential spillover effects that result when financial institutions withdraw funding from each other, instead of on the asset side. Thus, it is raw assets, rather than risk-weighted assets, that matter.

The U.S. authorities have continued to impose a leverage constraint on regulated banks, a practice at variance with the minimum capital requirements laid down in pillar I of the Basel II capital requirements. Recently, however, the authorities in Switzerland have announced their intention to introduce a U.S.-style leverage constraint. This announcement has generated a fierce controversy.

The most commonly encountered criticism of a raw leverage constraint is that it does not take account of the riskiness of the assets. Basel II rules specify a very finely graduated capital requirement that depends on minute shifts in the measured risk of the asset portfolio. A simple leverage ratio is seen as throwing away all these finely calibrated calculations of asset risk. The Financial Times recently quoted the chief risk officer of Credit Suisse, speaking in reaction to an announcement by Philipp Hildebrand, the vice chairman of the Swiss central bank, as saying, "we manage banks according to Basel II, not Hildebrand I." ${ }^{23}$ However, when viewed through the lens of systemic stability, the leverage ratio constraint has desirable properties that cannot be replicated by risk-based capital ratios alone.

Indeed, a leverage ratio constraint seems particularly appropriate for Switzerland. The country's two large banks, UBS and Credit Suisse, are both highly leveraged even by the standards of the U.S. investment banks, whose leverage ratios before the crisis were, as previously noted, around 30:1. (Commercial banks in the United States, also as previously noted, typically have much lower leverage ratios of 10:1 to 12:1.) The total assets of UBS at the end of 2007 were 2.27 trillion Swiss francs. With equity of only 42.5 billion Swiss francs, this implies a leverage ratio of 53:1. Although most of the assets on UBS's balance sheet are "safe" assets subject to a low capital requirement, we have seen that the credit risk weights do not always reflect the strength of the externalities in a financial system.

Two conceptual issues, however, need to be tackled in implementing a leverage ratio constraint; these have to do with the measurement of the two quantities involved in the definition of the leverage ratio. With regard to the numerator (total assets), the issue is what assets to include. In jurisdictions that apply the International Financial Reporting Standards (IFRS) of

23. “Taming Swiss Banks," Financial Times, online edition, July 1, 2008. 
Figure 11. Composition of Northern Rock's Liabilities, June 1998-June 2007

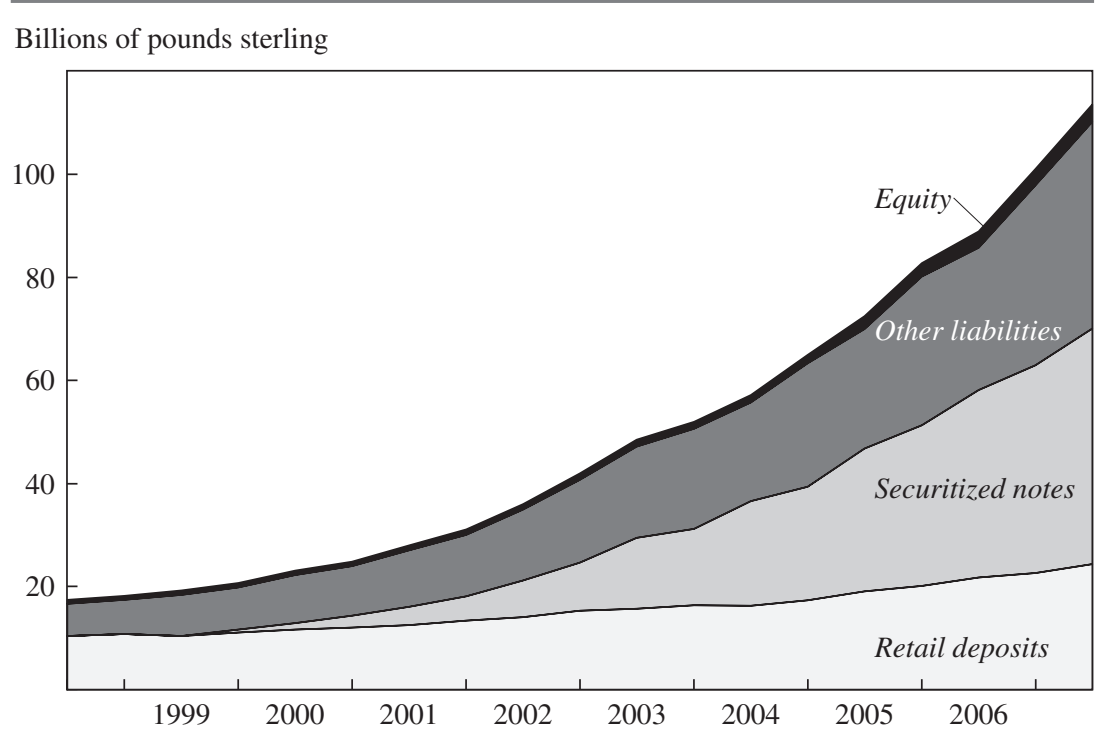

Source: Shin (forthcoming).

the International Accounting Standards Board, assets held in securitization vehicles are counted as part of the consolidated balance sheet. This raises the raw balance sheet size for European banks. (U.S. banks do not follow this standard.) For instance, figure 11 shows the liabilities side of Northern Rock's balance sheet in the 10 years from its demutualization in 1997 to its failure in 2007. Securitized assets accounted for much of the rapid increase in liabilities. ${ }^{24}$ The rapid growth of Northern Rock's assets therefore reflects the active securitization it engaged in after demutualization.

Another accounting issue with regard to assets is how to assess the fair value of derivatives contracts. Under IFRS, both mark-to-market gains and mark-to-market losses are included in calculating the consolidated balance sheet, making it appear much larger than it would otherwise. The very high leverage of UBS is therefore partly an accounting phenomenon. ${ }^{25}$

The issue with regard to the denominator-that is, equity-is again what should be counted. Figure 12 plots Northern Rock's leverage ratio from June 1998 to December 2007 according to three different measures of equity, with very different results depending on whether preferred

24. See Yorulmazer (2008) for an empirical analysis of the U.K. banking sector at the time of the Northern Rock crisis.

25. See "Banks According to GAAP," Financial Times, online edition, July 29, 2008. 
Figure 12. Northern Rock's Leverage under Various Definitions, 1998-2007

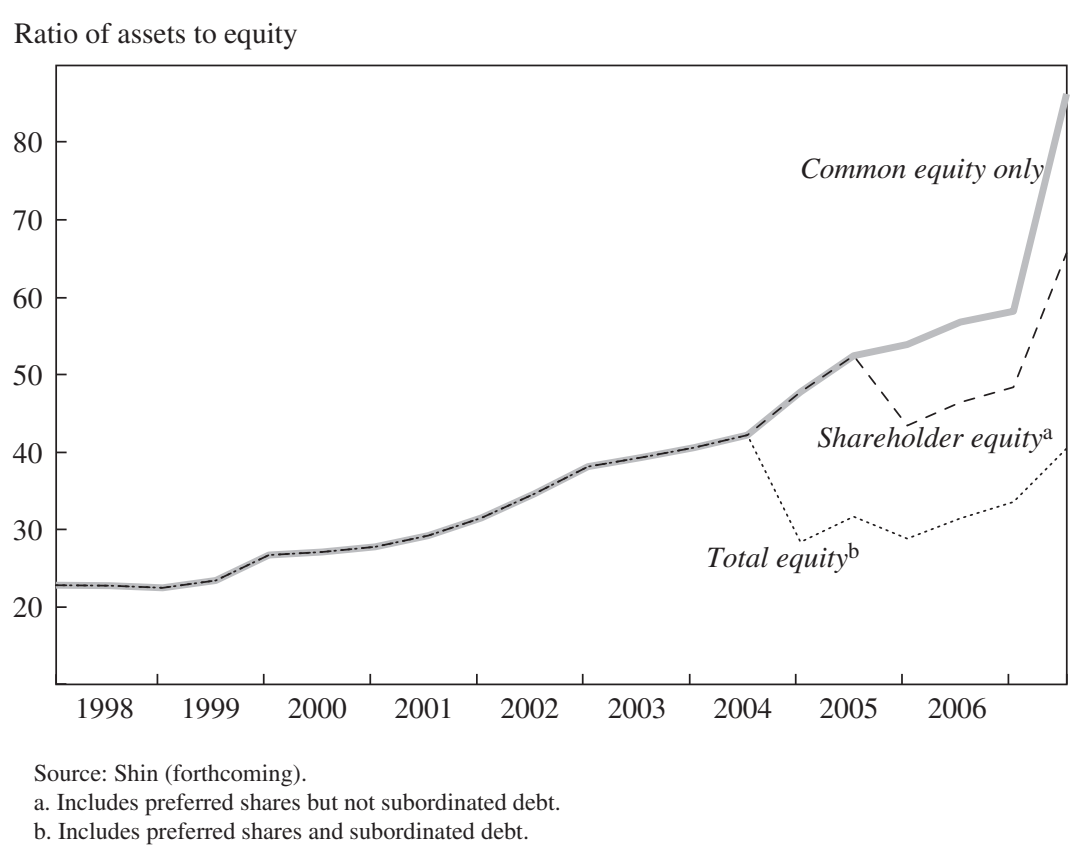

shares and subordinated debt are included. Under the Basel approach to capital requirements, both count as bank capital, since they are buffers against loss. However, repo haircuts provide another interpretation of equity, as the stake that the controlling equity holder must have in order to borrow credibly from creditors who worry about moral hazard. Tobias Adrian and Shin, and Arvind Krishnamurthy, provide theoretical rationales for such an approach to the leverage calculation, ${ }^{26}$ drawing on the work of Bengt Holmstrom and Jean Tirole. ${ }^{27}$

From this alternative viewpoint, subordinated debt holders and preferred shareholders are just another class of creditor to the bank, lacking the control of the bank's operations that common equity holders enjoy. For the purpose of calculating the permissible leverage in a moral hazard context, where the equity holders must have sufficient equity at stake to prevent moral hazard, it is the common equity that matters, not equity enhanced by subordinated debt or preferred shares.

26. Adrian and Shin (2008); Krishnamurthy (forthcoming).

27. Holmstrom and Tirole (1997). 
Figure 12 shows that when leverage is interpreted strictly as the ratio of total assets to common equity, Northern Rock's leverage continued to climb throughout its history as a public company, from 22.8:1 in June 1998, just after its flotation, to 58.2:1 in June 2007, on the eve of its liquidity crisis. This is a very large number, even by the standards of U.S. investment banks that hold very liquid and short-term assets. Of course, Northern Rock's leverage rose even higher following the depletion of its common equity from losses suffered in the second half of 2007 and the run that ensued. The leverage on its common equity at the end of 2007 was 86.3.

\section{Implications for Financial Regulation: System-Weighted Capital Requirements}

If we take seriously the idea that the computation of leverage ratios is an exercise in computing Pigovian taxes to limit externalities, then a natural follow-up question is how to assess the impact of the negative externalities imposed by one bank on the financial system as a whole. In the textbook example of the smoky factory located next to the laundry, the externality is the factory's pollution, and a calculation of marginal costs will enter into the appropriate Pigovian tax on the factory.

In the case of the financial system, the negative externalities are those that one institution imposes on another through fluctuations in funding conditions. In the example in figure 4, Bank 2 imposes a negative externality on Bank 1 if it decides to curb its collateralized lending. However, the impact of a similar decision by Bank 3 can be even greater, since a reduction in its lending will cause a reduction in lending by Bank 2, which in turn will induce a reduction in lending by Bank 1. If Bank 1's assets are illiquid, the withdrawal of funding may cause even greater damage.

More generally, one can assign each bank in the financial system a "systemic impact factor" that corresponds to the degree of spillover that its actions have on other banks. The exact calculation of the systemic impact factor will depend on the network structure and on the nature of the assets held by each bank. However, the principle should be that any bank that lends heavily to other banks that have high systemic impact factors should itself have a high systemic impact factor.

Such a principle could be implemented through the type of fixed-point calculation used, for example, in rating the impact of scholarly papers by their citations in academic journals, or in calculating the impact weights that Google uses to rank websites. The impact weights for journals are designed such that a high-impact journal receives many citations from 
other high-impact journals. Similarly, Google's rankings give higher rank to a website the more links point to it from other high-ranking websites. Indeed, our use of the term "impact factor" is intended to underline this analogy with journal citations and Google webpage rankings.

In practice, however, complex calculations on impact factors would be difficult to implement in a financial regulatory regime. The lack of detailed balance sheet information on banks' cross exposures is an insurmountable hurdle. Even so, the principle of giving high systemic weight to institutions that have the potential to affect others' actions seems sound.

In any case, the impact factors associated with financial institutions in the same or similar categories may naturally be clustered. For example, a broker-dealer may have a higher impact factor than a small, locally based savings institution that deals primarily with retail customers and household borrowers. Thus, the fragmented way in which financial intermediaries in the United States have been regulated may turn out to have a deeper, unintended economic rationale. A given institution of a given type can be assumed to have characteristics similar to others of its type and can therefore be regulated similarly, and differently from other types of institutions. However the systemic impact factors are calculated, the principle of Pigovian taxation-that negative externalities should be taxed appropriatelycan serve as a guide for our thinking.

An alternative approach in the practical implementation of systemweighted capital requirements would tie these requirements to summary statistical measures of spillovers, provided reliable summary measures could be obtained. A promising line of research is that reported in Adrian and Markus Brunnermeier, who consider the concept of "CoVar," defined as the value at risk of an institution's portfolio of assets conditional on some aggregate measure of distress. ${ }^{28}$ Although some conceptual issues relating to aggregation and the endogeneity of the portfolios in response to incentives to game the regulatory system still need to be worked out, the approach is a promising one.

\section{Concluding Remarks}

The traditional approach to financial regulation based on risk-based capital requirements is not well suited to addressing the issue of the stability of the financial system as a whole. The truism that taking care of the solvency of

28. Adrian and Brunnermeier (2008). 
each individual institution ensures the stability of the system is not useful, because it does not address spillover effects.

The most important distinction that the system perspective highlights is that between risky assets and systemically important assets. Even safe assets can be systemically important. Recognizing this distinction gives some rationale for two policy ideas that have attracted much attention: that of imposing a raw leverage constraint, and that of having a liquidity requirement that limits the composition of the asset portfolio, not merely its size. More systematic study will reveal how onerous the corresponding Pigovian taxes will have to be, but the severity of the current financial crisis suggests that the optimal Pigovian taxes will not be zero.

ACKNOWLEDGMENTS We are grateful to the participants at the Brookings Panel conference for their comments, and especially to our discussants Donald Kohn and Vincent Reinhart. We also thank Tobias Adrian and Charles Goodhart for comments on an earlier draft. 


\section{References}

Adrian, Tobias, and Markus Brunnermeier. 2008. "CoVaR.” Federal Reserve Bank of New York Staff Report 348. New York.

Adrian, Tobias, and Hyun Song Shin. Forthcoming. "Liquidity and Leverage." Journal of Financial Intermediation.

- 2008. "Financial Intermediary Leverage and Value at Risk." Federal Reserve Bank of New York Staff Report 338. New York.

Allen, Franklin, and Douglas Gale. 2000. "Financial Contagion." Journal of Political Economy 108, no. 1: 1-33.

Bair, Sheila. 2006. Remarks at the Conference on International Financial Instability: Cross-Border Banking and National Regulation, sponsored by the Federal Reserve Bank of Chicago and the International Association of Deposit Insurers, October 5. www.fdic.gov/news/news/speeches/archives/2006/chairman/ spoct0606.html.

Bank of England. 2008. Financial Stability Report no. 23. London (April). www.bankofengland.co.uk/publications/fsr/2008/fsrfull0804.pdf.

Bernanke, Ben. 2008. "Reducing Systemic Risk." Speech at the Federal Reserve Bank of Kansas City Symposium at Jackson Hole, Wyo., August 22. www. federalreserve.gov/newsevents/speech/bernanke20080822a.htm.

Brunnermeier, Markus. 2009. "Deciphering the 2007-08 Liquidity and Credit Crunch." Journal of Economic Perspectives 23, no. 1. Forthcoming.

Brunnermeier, Markus, and Lasse Pedersen. Forthcoming. "Market Liquidity and Funding Liquidity." Review of Financial Studies.

Bryant, John. 1980. "A Model of Reserves, Bank Runs and Deposit Insurance." Journal of Banking and Finance 4, no. 4: 335-44.

Crockett, Andrew. 2000. "Marrying the Micro- and Macro-Prudential Dimensions of Financial Stability.” Bank for International Settlements, Basel. www.bis.org/ review/rr000921b.pdf.

Dewatripont, Mathias, and Jean Tirole. 1994. The Prudential Regulation of Banks. Cambridge, Mass.: MIT Press.

Diamond, Douglas, and Philip Dybvig. 1983. "Bank Runs, Deposit Insurance, and Liquidity." Journal of Political Economy 91, no. 3: 401-19.

Fisher, Peter. 2008. "Role of Liquidity in Financial Crises." Commentary at the Federal Reserve Bank of Kansas City Symposium at Jackson Hole, Wyo., August 23. www.kc.frb.org/publicat/sympos/2008/fisher.09.01.08.pdf.

Holmstrom, Bengt, and Jean Tirole. 1997. "Financial Intermediation, Loanable Funds, and the Real Sector." Quarterly Journal of Economics 112, no. 3: 663-91.

Kashyap, Anil, Raghuram Rajan, and Jeremy Stein. 2008. "Rethinking Capital Regulation." Paper presented at the Federal Reserve Bank of Kansas City Symposium at Jackson Hole, Wyo., August 23. www.kc.frb.org/publicat/sympos/ 2008/KashyapRajanStein.09.15.08.pdf.

Krishnamurthy, Arvind. Forthcoming. "Amplification Mechanisms in Liquidity Crises." American Economic Journal: Macroeconomics. 
Morris, Stephen, and Hyun Song Shin. 1998. "Unique Equilibrium in a Model of Self-Fulfilling Currency Attacks." American Economic Review 88, no. 3: $587-97$.

. 2002 "Measuring Strategic Uncertainty." Princeton University. www. princeton.edu/ hsshin/www/barcelona.pdf.

—. 2004. "Liquidity Black Holes." Review of Finance 8, no. 1: 1-18.

. 2008. "Identifying the Illiquidity Component of Credit Risk." Working paper. Princeton University.

Shin, Hyun Song. Forthcoming. "Reflections on Northern Rock: The Bank Run that Heralded the Global Financial Crisis." Journal of Economic Perspectives.

Summers, Lawrence. 2000. "International Financial Crises: Causes, Prevention and Cures." American Economic Review: Papers and Proceedings 90, no. 2: 1-16.

Yorulmazer, Tanju. 2008. "Liquidity, Bank Runs and Bailouts: Spillover Effects during the Northern Rock Episode.” Working paper. Federal Reserve Bank of New York. 


\section{Comments and Discussion}

\section{COMMENT BY}

DONALD L. KOHN I appreciate the opportunity to comment on these three papers. They illuminate the sources and effects of the current financial market turmoil, and I learned a considerable amount from reading them and thinking about their implications. Instead of providing detailed comments on each paper, I would like to draw out the relationships among them and, in the process, comment a little on the papers and their implications. To foreshadow: I will be highlighting the role of leverage-in the household sector and in financial intermediaries-as a critical factor in understanding the buildup of excesses and their unwinding.

At the beginning of the chain of causation is the housing cycle in the United States. Karl Case points out the difference between this housing cycle and others over past decades and asks why the difference developed. One culprit he identifies is changes in the financial system that affected the way that mortgage credit is made available to borrowers. A key element of these changes, and one that accounts for a good part of the subsequent effects on the financial system and the economy, is the rise in leverage in housing finance. For several years mortgage indebtedness rose substantially relative to the value of owner-occupied housing. The willingness of lenders to tolerate - or, in some cases, encourage-huge increases in loanto-value ratios added to the demand for housing, especially by people who normally might not have had the savings to enter the market, and contributed to the rise in home prices.

One reason for the loosening of standards was the expectation that home prices would continue to rise-and even more certainly that they

The views I express are my own and not necessarily those of other members of the Board of Governors of the Federal Reserve. 
could not fall in all regions at the same time, supporting diversification through securitization. Rising prices would enable lenders to recoup their funds even if the borrower was unable to service the loan, mostly because the borrower would be able to obtain extra cash through refinancing. Expectations of home price appreciation facilitated and interacted with the increasing complexity of mortgage securities, including multiple securitizations of the same loan, which made it virtually impossible for ultimate lenders to monitor the creditworthiness of borrowers-a task they, in effect, had outsourced to credit rating agencies. The absence of investor caution and due diligence was especially noticeable for the highest-rated tranches of securitized debt.

Elevated leverage in housing markets has meant that as prices have fallen, lenders have had to absorb an unusually high proportion of the losses. As Case points out, foreclosures by lenders have added to the downward pressure on those prices. Conceptually, such price declines moving down the demand curve for housing services could accelerate and cushion the adjustment in activity necessitated by previous overbuilding.

The heavy involvement of financial intermediaries in amplifying the housing boom and the subsequent economic effects of the bust brings me to the paper by Stephen Morris and Hyun Song Shin, which raises a host of important issues related to the systemic aspects of financial intermediation and the lessons from the recent turmoil. As they emphasize, one of the important lessons has been the greater-than-expected vulnerability of secured financing when intermediaries are engaged in maturity, credit, and liquidity transformation. Recall that the turmoil first came onto the balance sheets of the banks through the collapse of the asset-backed commercial paper market in the fall of 2007, before it affected the funding of investment banks through the triparty repurchase agreement market. The new vulnerability results importantly from the extension of secured short-term financing to increasingly illiquid and riskier long-term assets. As the liquidity and creditworthiness of those assets-especially related to mortgage-backed securities-were called into question, lenders became more concerned about the possibility that they might end up owning the underlying assets, and they raised haircuts or simply refused to roll over loans.

Clearly, as Morris and Shin point out, what we have learned about various risks implies the need for intermediaries to build greater liquidity and capital buffers in good times, as well as to improve their abilities to manage their risks. And those larger buffers would help to offset the moral haz- 
ard that may have been created through the expansion of liquidity facilities at the Federal Reserve. Getting the microprudential piece right-having each institution adequately protected-would go a long way toward making the whole system more robust and resilient.

But Morris and Shin would go further; they would impose additional requirements on institutions to take account of the externalities for the system created when common shocks impair markets and credit availability by provoking widespread actions to preserve shareholder value. They would do this through a higher liquidity requirement and through the imposition of a leverage ratio on investment banks, which is already in place for commercial banks.

I agree with the authors, and with Federal Reserve Chairman Ben Bernanke, that we need to consider the level of buffers that is appropriate to ameliorate systemic risk. That said, a host of difficult judgments are inherent in how we establish such a system, and I will raise just a few on a very general level. One set concerns the size of the buffers. How far into the tail of the distribution of possible outcomes should intermediaries be required to insure themselves? Shouldn't the Federal Reserve take some of the liquidity tail risk, to facilitate intermediation of illiquid credits, as was intended at its founding? Moreover, the larger the regulatory tax, the more likely it is that activity will migrate to unregulated sectors in an environment of fluid and free capital movements. How can we gain better assurance of systemic stability when we are unlikely to be able to continuously extend the reach of regulation, and will it be sufficient to deepen the moats around the core institutions? In this regard, the leverage ratio gives incentives to move some activities away from regulated institutions.

A second question is, How we can structure these requirements and other aspects of regulation to damp, rather than reinforce, the natural procyclical tendencies of the financial system? Among the challenges will be encouraging firms and supervisors to comfortably allow buffers to be eroded in bad times. Interestingly, prompt corrective action under the Federal Deposit Insurance Corporation Improvement Act of 1991 was intended, in part, to induce an element of countercyclical behavior by banks. It gives banks an incentive to build excess capital—on both a riskbased and a leverage ratio basis-in good times to avoid the need for prompt corrective action when circumstances are less favorable. Now that we are in the latter state of the world, a study of how commercial banks are viewing capital ratios, including the leverage ratio, could inform consideration of the Morris and Shin proposal. 
The Morris and Shin paper also provides a framework for thinking about the Federal Reserve's credit facilities. They note that liquidity makes borrowers feel more robust and lenders less likely to withdraw, raising the odds for a more stable equilibrium for the entire system. That is exactly what the Federal Reserve has been trying to do with its various discount lending facilities. The assurance of the availability of liquidity to sound institutions against good collateral should counter the greater uncertainty and risk aversion that have impaired normal arbitrage and intermediary functions, by making those institutions more willing to extend credit and take positions in the process of making markets. It should also assure other creditors of those institutions that illiquid markets will not impede the repayment of their loans, and therefore make them more willing to keep lending. A number of markets remain disrupted and illiquid. But I believe that they would have been even more illiquid, and the risk of disruptive runs even greater, without those various facilities; that is certainly what market participants are telling us.

The paper by Jan Hatzius tries to gauge the combined effects on aggregate spending of the losses generated by the effects of the decline in housing prices outlined in the Case paper and the impulse for deleveraging in the financial sector inherent in the processes discussed by Morris and Shin. To restore capital ratios depleted by mortgage losses and to raise those ratios even further in order to reduce leverage to the safer levels demanded by counterparties, banks and other lenders need to reduce assets. They do so by tightening terms and standards across a broad array of credit—and we at the Federal Reserve have seen this behavior reflected in our surveys of bank lending officers and in various spreads and other measures of risk perceptions, risk aversion, and reduced supply of credit at benchmark interest rates. In the current circumstances, some of the tightening we have seen has been in anticipation of possible adverse events in the economy and in confidence toward the financial sector. These types of actions not only move up the demand-for-credit curve, but also bolster profits going forward to cover potential write-offs and to attract new equity capital. Pressures on profits arise not only from write-offs, but also because some sources of earnings, like securitization of mortgages or leveraged loans, are no longer available.

In the steady state, lenders will get greater returns for taking risk than they did two years ago, intermediaries will be less leveraged and better capitalized, and the financial system will be more robust and resilient to shocks. The transition to the new steady state, however, as lenders deleverage and protect themselves against various downside risks, involves some 
overshooting - making terms and standards tighter than will be necessary over the long run.

This story is completely consistent with the one told in the Hatzius paper, which relies mostly on quantity relationships to gauge the possible effects on GDP. My instinct has been to go from the actual and expected indicators of tightening supply, such as the instrumental variables used in the paper, directly to estimates of the effects of that supply shift on GDP. Measures of flows would fall out of that exercise but would not be its focus. And I have questions about the stability and reliability of the debt-GDP relationship used in the forecasts at the end of the paper. But I will admit that we are in uncharted waters here, and the navigators should not discard any potential information about the location of the shoals.

The message of Hatzius's paper is that restraint on credit supplies is likely to persist because intermediaries have some way to go to rebuild their balance sheets. The process of adjustment to a safer, more resilient financial system is going to take a while. I agree with this observation.

\section{COMMENT BY}

VINCENT R. REINHART I appreciate the invitation to discuss these three fascinating papers focused on the important topic of the ongoing financial crisis. I will take this opportunity, first, to identify the commonality among them. Second, I will argue that a factor that is central to understanding recent financial market events is missing, both from these papers and in policymaking circles, at least judging from the actions of officials. Last, I will offer specific comments on each paper.

Over the past year, the chief impediment to aggregate spending in the United States and the major concern of policymakers has been that an adverse dynamic has taken hold. As can be seen working clockwise from the left of the simple schematic in my figure 1, the initiating economic loss came from building too many houses over the last decade. The efforts of builders to cope with bloated inventories have imposed a direct drag on spending. Home price declines, set in motion once this imbalance was recognized, have lowered wealth and consumption. The declines in home prices have also been associated with an elevated rate of mortgage foreclosures, which have strained the balance sheets of key financial intermediaries. The result has been that financial institutions are not supporting markets or making credit available, which further hampers spending and makes people less likely to buy houses. 
Figure 1. Transmission of a Housing Market Shock

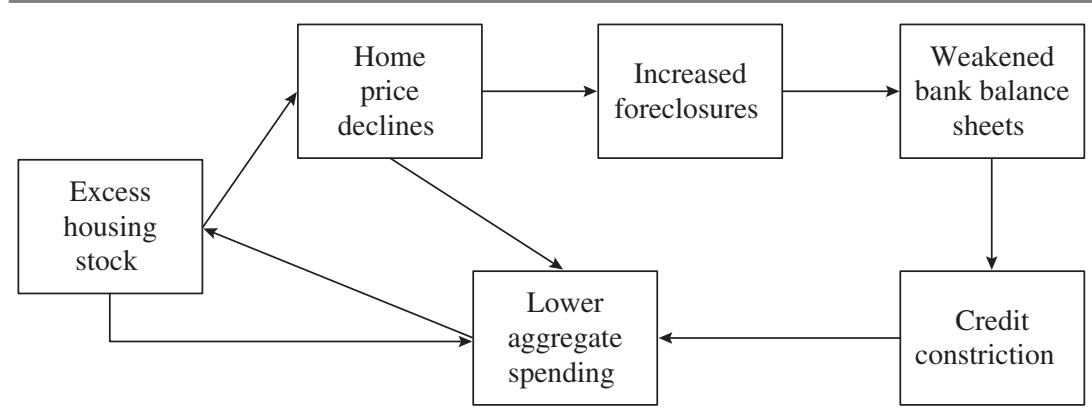

Source: Author's elaboration.

All three papers address this dynamic transmission mechanism, each focusing on a different aspect. Karl Case looks at the first part of that mechanism, namely, the relationship between the excess housing stock and home price declines. Jan Hatzius examines the macroeconomic mechanisms set in motion by home price declines. These include the restraint on spending through the direct wealth effect and the constriction of credit, that is, the financial accelerator. Finally, Stephen Morris and Hyun Song Shin address the interaction of financial institutions' balance sheets and credit constriction, and ask why the approximately $\$ 1$ trillion loss from the surge of mortgage defaults has so impaired balance sheets and produced such a huge drag on an economy as large as the United States.

My central problem with these papers-and it is a problem shared by policymakers - is that they treat this map of the economics of home price adjustment as conceptually identical to a weather map. That is, they regard financial market problems as a force of nature imposed on the economy with a path invariant to policy. When the authors and policymakers talk about "the perfect storm" or "the hundred-year flood," they are revealing a belief that they have no influence on the route of the storm. These descriptions neglect the possibility that policy has itself shaped the contours of the crisis. Market activity and asset pricing have important expectational components. The determination of asset prices involves issues related to the coordination of beliefs and may tend toward multiple equilibriums. ${ }^{1}$ As a result, even small policy actions can have large effects on the market. And the policy actions taken were not small.

1. A simple model of market activity addressing some of these issues is provided in Vincent R. Reinhart and Brian P. Sack, "The Economic Consequences of Disappearing Government Debt,” BPEA, no. 2 (2000): 163-209. 
In addition, policy interventions by the Federal Reserve and the Treasury in 2008, which were ambiguous in the scale and scope of the protections offered, created adverse incentives. The managers of firms with capital deficiencies were given the incentive to postpone adjustment. Creditors and short sellers were given the incentive to test the limits of government intervention. The net effect has been to deter private capital from flowing into an industry desperately in need of more capital.

Let me now turn to the individual papers. Karl Case assesses the economic loss that set the crisis in motion by examining the central role of home prices. The important message of that paper, although he does not put it exactly this way, is that home prices do not behave like other asset prices. This is evident in my figure 2. Each panel plots the quarterly return of an index of asset prices along the vertical axis against its own quarterly lagged return, over the period from 1991Q1 to 2008Q2. The top panel plots the change in the Case-Shiller national home price index. It shows that home prices are very predictable: last quarter's return sends a strong signal of what this quarter's return will be. That is nowhere near the case in the bottom panel, which plots the change in the S\&P500 index against its own lag. Stock prices are more predictable than simple theory may suggest, but they are not very predictable. ${ }^{2}$

Why do home prices show such inertia? Sellers have discretion with respect to the listed price, advertising intensity, time on the market, and inclusion of amenities. Buyers have discretion on search intensities and time in the market. These are mechanisms that make prices sticky, but they are not the underlying reasons for this stickiness.

Two sets of insights from the macroeconomic literature may help in understanding the underlying source. This literature posits that prices can be inertial because of staggered contracting, menu costs, or sticky information. With respect to all three, price dynamics can be thought of as actual prices moving gradually toward a flexible shadow price. In the current environment, once the overhang of unsold homes became evident to the public, shadow prices fell. Now we are living through the inertial catch-up of transaction prices to those lower shadow prices. The relevant issue in explaining the overall economic adjustment is to determine which behaviors depend on shadow prices and which depend on transaction prices. Presumably, households' assessments of their own wealth, for instance,

2. James M. Poterba and Lawrence H. Summers, "Mean Reversion in Stock Prices: Evidence and Implications," Working Paper 2343 (Cambridge, Mass.: National Bureau of Economic Research, 1989), provide evidence of the modest predictability of stock returns over a long sample. 
Figure 2. Correlations of Current with Lagged Changes in Asset Prices ${ }^{a}$

\section{Home prices}

Change in current quarter (percent)

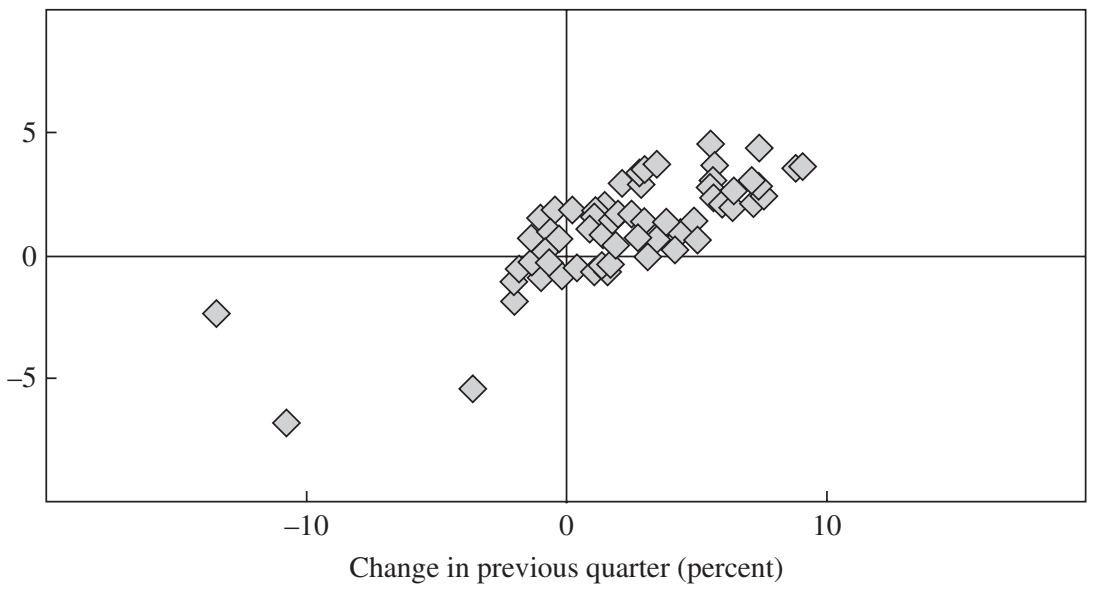

Stock prices

Change in current quarter (percent)

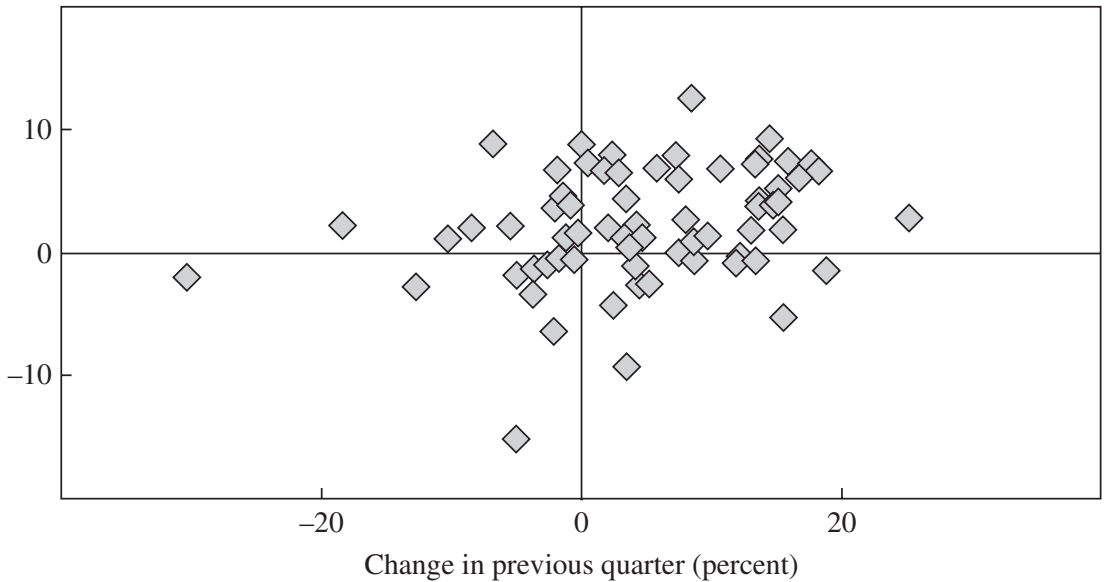

Sources: Standard \& Poor's; author's calculations.

a. Quarterly changes in the S\&P/Case-Shiller National Home Price Index (top panel) or the S\&P500 index (bottom panel), 1991Q2-2008Q2. 
Figure 3. OFHEO and Case-Shiller National Home Price Indexes, 1991Q1-2008Q2

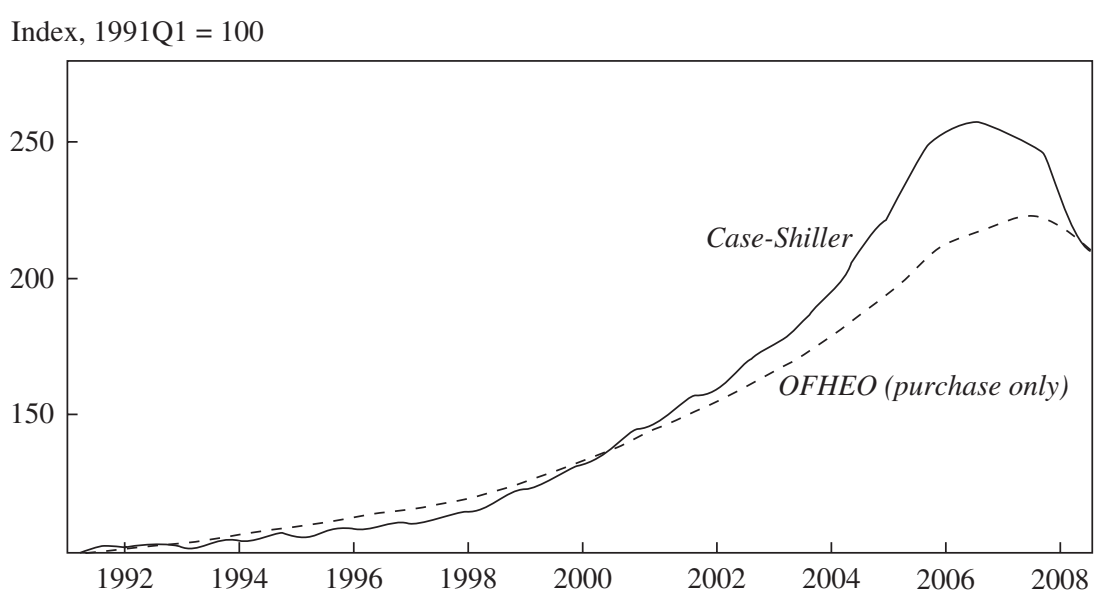

Sources: Office of Federal Housing Enterprise Oversight; Standard \& Poor's.

relate to their beliefs about resale values, reflected in shadow prices. Credit constraints, in contrast, depend on the value of a home as collateral and, more likely operationally, are related to transaction prices. But that is an issue for macroeconomic theorists, and Case has provided many interesting empirical regularities for them to try to match.

Jan Hatzius addresses the broader economic consequences of declining home prices. His paper takes a careful, disaggregated approach, articulating the channels of influence that home prices have on macroeconomic activity. It takes advantage of regional variation in home prices, for which there is some precedent for the significant declines once thought impossible at the national level. It acknowledges, but does not always address, the econometric complications due to data limitations.

I would like to make three main points, from small to large, about Hatzius's paper. First, in his disaggregated description of the channels of the effects of home price changes, Hatzius uses auxiliary regressions to explain the change in the Office of Federal Housing Enterprise Oversight (OFHEO) state indexes with the change in the Case-Shiller national price index. ${ }^{3}$ However, at the national level, as seen in my figure 3 , the OFHEO

3. See Charles Calomiris, Stanley D. Longhofer, and William Miles, "The ForeclosureHouse Price Nexus: Lessons from the 2007-2008 Housing Turmoil," Working Paper 14294 (Cambridge, Mass.: National Bureau of Economic Research, 2008), for a discussion of these price indexes. 
and Case-Shiller price series begin and end at the same points 17 years apart. A change-on-change regression cannot explain this convergence. An error correction model, in contrast, would do a better job of explaining the two national series. This is more than an econometric nicety: it could have consequences for the long-run scenarios analyzed in the paper.

Second, a significant doctrinal history about the predictive relationship of debt on macroeconomic activity, which the paper also examines, has been part of Brookings Panel discussions over the past three decades. One reason that the Federal Reserve for some time had an aggregate debt measure, for instance, was the contributions made by Benjamin Friedman. ${ }^{4}$ That literature discusses many aspects of the econometric difficulties in estimation and should be referenced.

Third, in calling attention to the critical role of the governmentsponsored enterprises, the paper identifies an important public policy issue. If Fannie Mae and Freddie Mac are required to shrink their balance sheets along with everyone else, the macroeconomic losses will be considerably larger. Therein lies the uncomfortable choice for the Treasury. Were those two firms placed under conservatorship in order to bolster their creditworthiness, or in order to use their balance sheets to offset the unusual restraint in the mortgage market?

Morris and Shin study the effects of balance sheet adjustment, given the decline in home prices, on the financial system as a whole. They are to be credited for examining the issues in terms of first principles, offering a different perspective on the map of the ongoing economic adjustment. That perspective is especially important for understanding the aggregate consequences of individual behavior.

However, a risk of using a separate analytical framework to explain this adjustment is that it can become detached from the existing understanding of the underlying behavior that has led to market failure. It also invites bureaucratic capture of "systemic risk management," adding another layer between the regulators and market activity.

An example of the first risk can be seen in their proposition 1. Morris and Shin explain that "actions that enhance the soundness of an individual institution may undermine the stability of the system as a whole." This would have been much clearer to me had it been explained as a

4. See, for example, Benjamin M. Friedman, "Crowding Out or Crowding In? Economic Consequences of Financing Government Deficits," BPEA, no. 3 (1978): 593-641, and "The Roles of Money and Credit in Macroeconomic Analysis," Working Paper 831 (Cambridge, Mass.: National Bureau of Economic Research, 1981). 
simple fallacy of composition, which is a concept as old as the field of macroeconomics.

Another example is their proposition 3, which distinguishes between risky assets and systemically important assets. The idea that an asset can serve multiple roles, and that its price can reflect those roles, is not new. For instance, Darrell Duffie has shown rigorously that the prices of Treasury securities incorporate their usefulness as collateral in repurchase transactions. ${ }^{5}$ In that regard, price premiums on some Treasury securities serve as a "canary in the coal mine" indicating marked aversion to risk. Similarly, Lubos Pastor and Robert Stambaugh have shown that asset prices include a loading on the risk of illiquidity. ${ }^{6}$ From this perspective, there is something that economists do not yet understand about expectation formation, the shape of the utility function, and coordination among agents that every so often puts a high price on this tail risk.

To sum up, these three papers provide a clear review of the channels through which home price declines affect the broader economy. They are essential reading for understanding the ongoing global financial crisis. However, absent from them is a discussion of an important role for expectations that could produce herding and self-fulfilling prophecies. In such an environment, policy matters for more than just shaping long-run incentives. Policy can influence immediate market outcomes, and not always for the best.

GENERAL DISCUSSION Martin Baily remarked that despite the common belief that the rise in home prices had been in large measure responsible for the current crisis, he himself placed much of the blame on the regulatory regime and the decline in lending standards. The sharp rise in foreclosure rates among more recent vintages of mortgages was evidence of such laxity, he argued.

Robert Hall noted that the impact of credit cutbacks has varied greatly across economic sectors: nonfinancial corporate businesses have remained largely unaffected so far, since the corporate sector, in the aggregate, has negative leverage. This would explain why real GDP continued to climb despite the credit crisis.

5. Darrell Duffie, "Special Repo Rates," Journal of Finance 51, no. 2 (1996): 493-526.

6. Lubos Pastor and Robert F. Stambaugh, "Liquidity Risk and Expected Stock Returns," Journal of Political Economy 111, no. 3 (2003): 642-85. 
Paul Willen commented on the specification of regressions that include foreclosure rates. Changes in the foreclosure rates calculated by the Mortgage Bankers Association are driven both by changes in the numerator (the number of foreclosures of a given type of loan) and by changes in the denominator (the number of existing loans of that type); much of the recent volatility comes from volatility in the denominator. No new subprime loans are being made, and therefore the foreclosure rate for subprime loans is necessarily increasing. Thus, the recent movement in the foreclosure rate reflects mainly changes in the composition of the mortgage pool. Willen also mentioned that the level of, not the change in, home prices matters particularly with regard to the fraction of the population with negative equity: homeowners with negative equity who experience a negative shock to their ability to pay will go into foreclosure even if overall home prices have stabilized.

Olivier Blanchard suggested that rather than analyze home prices by themselves, one should look at the ratio of home prices to some other indicator, such as average rent. He also mentioned that price increases could have come from decreases in user costs, given that real interest rates and risk premiums were so low. He also wondered how much confidence one should have in the Case-Shiller futures data, which he viewed as alarming.

Andreas Lehnert mentioned several recent papers dealing with the issue of rent-to-price ratios. Several papers by Joshua Gallin at the Federal Reserve have established the tight link between rents and prices, and a paper that he himself had co-written had looked at trends in the rate of return on housing. He questioned the causal link between lending and GDP: he argued that projects with positive net present value should get funding unless quantity rationing or institutional distress limited lending. He also mused about the incredibly tight link between mortgage debt growth and home price growth. This link does not necessarily reflect a causal effect of borrowing on prices but may reveal less demand for credit when declining home prices make homes a less desirable investment. Lastly, he pointed out several institutional differences between housing markets in the United States and those in other countries and wondered about their implications and the reasons for the differences.

Benjamin Friedman observed that the impact of credit market stringency on the economy is likely to exceed that of declining household wealth. He also wondered whether the relationship between credit markets and the real economy will resemble in the future what it has been in the past. Lastly, he remarked that investment banks require high leverage 
ratios in order to be profitable. Should they be forced to deleverage, banks will have to develop new business models in order to stay profitable.

Bradford DeLong opined that one reason the crisis occurred was not that the market mistakenly accepted the triple-A ratings of risky tranches of subprime debt, but rather that the originators did not want to pay the rate that the market required to hold those tranches, and therefore required their own portfolio managers to hold those securities at par despite their institutions' high leverage ratios. He also wondered why the global financial markets did not mobilize the risk-bearing capacity of the global economy to spread the risk of a housing downturn.

Alan Blinder questioned the authors' downplaying of the importance of the role played by imprudent mortgage lending and the derivatives built on top of that lending. He also noted that the Basel capital standards have caused distortions and that measuring debt with a simple leverage ratio cannot be correct, since different forms of debt, such as Treasury bills, bank loans, or collateralized debt obligations, can produce the same leverage ratio.

Robert Gordon suggested that some of the ratios used in the papers should be rethought. For example, the population has doubled and the economy has grown by a factor of four or five over the past several decades. Thus, housing starts should be expressed as a ratio to the number of households. Additionally, it is not correct to deflate a home price index by real income per capita, because the income elasticity of housing quality is positive: households buy not only bigger but also better homes as their income rises. The Case-Shiller and OFHEO indices are inherently adjusted for quality because they consider repeat sales of the same homes. One could also look at real residential wealth per capita divided by real income per capita, or at the real value of residential construction divided by real income per capita. He also noted that movements in housing prices do not entirely explain the crisis. Declining lending standards are also to blame, as people were given mortgages that exceeded income constraints on monthly mortgage payments. 